This is the final peer-reviewed accepted manuscript of:

Viciano J.; Tanga C.; D'Anastasio R.; Belcastro M. G.; Capasso L.: Sex estimation by odontometrics of nonadult human remains from a contemporary Italian sample. AMERICAN JOURNAL OF PHYSICAL ANTHROPOLOGY 175. 0002-9483

DOI: 10.1002/ajpa.24132

The final published version is available online at: http://dx.doi.org/10.1002/ajpa.24132

Rights / License:

The terms and conditions for the reuse of this version of the manuscript are specified in the publishing policy. For all terms of use and more information see the publisher's website.

This item was downloaded from IRIS Università di Bologna (https://cris.unibo.it/)

When citing, please refer to the published version. 


\title{
Sex estimation by odontometrics of nonadult human remains from a contemporary Italian sample
}

\author{
Joan Viciano ${ }^{1,} 2$ Carmen Tanga ${ }^{1}$ Ruggero D'Anastasio ${ }^{1,2}$ \\ Maria Giovanna Belcastro $^{3}$ Luigi Capasso ${ }^{1}$,2
}

${ }^{1}$ Operative Unit of Anthropology, Department

of Medicine and Ageing Sciences, 'G.

d'Annunzio' University of Chieti Pescara,

Chieti, Italy

'University Museum, 'G. d'Annunzio'

University of Chieti Pescara, Chieti, Italy

${ }^{3}$ Department of Biological, Geological and

Environmental Sciences, Alma Mater

Studiorum, University of Bologna, Bologna,

Italy

Correspondence

Joan Viciano, Operative Unit of Anthropology, Department of Medicine and Ageing Sciences, 'G. d'Annunzio' University of Chieti Pescara, Piazza Trento e Trieste 1, 66100 Chieti, Italy. Email: joan.viciano@unich.it

\begin{abstract}
Objectives: The objective was to develop an odontometric technique for sex estimation based on dental measurements from adult individuals, and to evaluate its applicability and reliability for diagnosis of sex of nonadult skeletal remains.

Materials and methods: This study was conducted on the permanent dentition of 132 individuals (70 males, 62 females) from the identified human skeletal collection of the Certosa Cemetery (Bologna, Italy) of the University of Bologna. Binary logistic regression equations were developed based on dental measurements of the permanent teeth of the adult individuals, and these equations were subsequently applied to the permanent dentition of nonadult individuals to estimate their sex.

Results: These data show that the canine teeth of both the maxilla and mandible are the most sexually dimorphic teeth in adults, followed by the mandibular second molar, maxillary and mandibular second and first premolars, and mandibular first molar. These data provided correct assignment of sex in $80.4-94.9 \%$ of cases, which depended on the measurements used. Of the 26 nonadult individuals of the experimental sample, sex diagnosis was possible for 22 , which represented an applicability rate of $84.6 \%$ of the individuals. Comparing the sex of these 22 nonadult individuals estimated by odontometrics with the known biological sex, correct assignment was obtained in $90.9 \%$ of cases.

Conclusion: As a method of sex estimation, odontometric analysis of permanent dentition can be used successfully for nonadult human skeletal remains in both forensic and archeological contexts.
\end{abstract}

KE YWOR DS

binary logistic regression, odontometry, sexual dimorphism, subadults, tooth size
1 INTRODUCTION

Sex estimation of nonadult human skeletal remains with satisfactory accuracy is a recognized problem in physical anthropology. This represents a challenge in medico-legal assessments, as well as in other studies of both ancient and recent skeletal remains. The problem arises because expression of sex-related skeletal characteristics is mainly due to the changes in hormone levels at puberty. Thus, in individuals who have not yet reached puberty and have not yet matured sexually, the discernment of sexual skeletal characteristics is minimal (Cardoso, 2008; Lewis, 2006).

Estimation of sex of nonadult skeletal remains has been reported, with this most frequently being based on the use of the same skeletal characteristics known to be accurate for sex assessment in adults, as mainly morphological traits of the pelvis (Irurita \& Alemán, 2016; Luna, Aranda, \& Santos, 2017; Schutkowski, 1993; Sutter, 2003; Vlak, 
Roksandic, \& Schillaci, 2008; Weaver, 1980) and the cranium (Franklin, Oxnard, O'Higgins, \& Dadour, 2007; Irurita \& Alemán, 2016; Loth \& Henneberg, 2001; Molleson, Cruse, \& Mays, 1998; Schutkowski, 1993).

However, as some subjectivity is involved in such descriptive skeletal morphology because of the difficulty to consistently assign a score to a specific feature, these methods have been criticized for high rates of intraexaminer and interexaminer errors (Cardoso \& Saunders, 2008; Krishan et al., 2016). To circumvent these complications, studies have been designed to develop further skeletal metric methods for sex estimation (Stull \& Godde, 2013; Stull, L'Abbé, \& Ousley, 2017). Although these metric methods have been reported to be more repeatable than descriptive morphological methods (Bartlett \& Frost, 2008; Ulijaszek \& Kerr, 1999), they have proven to be of limited use for accurate sex estimation. Such metric methods depend on the integrity of the skeletal remains under the usual circumstances of the fragmented state of preservation of fragile remains of nonadult individuals recovered in forensic and archeological contexts. In addition, these measurements tend to be population specific.

Odontometrics is a valuable technique for sex estimation, particularly as teeth are often better preserved than bone tissue due to their hardness, durability and resistance to postdepositional processes (Duckworth, 2006; Gouveia, Oliveira Santos, Santos, \& Gonçalves, 2017; Schmidt \& Symes, 2015). Therefore, teeth are often more represented in human skeletal samples when the bones are in decayed and/or fragmented conditions (Hillson, 1996). Over the last 60 years, following the study of Hunt Jr and Gleiser (1955) about sex estimation from osseous and dental remains of nonadult individuals, analyses have been carried out to determine a reliable method for sex estimation from teeth. Thus, numerous studies have quantified sexually dimorphic differences between males and females through odontometric techniques, with the demonstration that sexual dimorphism results in larger teeth in males than females in permanent dentition (Adams \& Pilloud, 2019; Angadi, Hemani, Prabhu, \& Acharya, 2013; Capitaneanu, Willems, Jacobs, Fieuws, \& Thevissen, 2017; Hassett, 2011; Kazzazi \& Kranioti, 2017, 2018; Khamis, Taylor, Malik, \& Townsend, 2014; Luna, 2019; Peckmann, Logar, Garrido-Varas, Meek, \& Pinto, 2016; Peckmann, Meek, Dilkie, \& Mussett, 2015; Shaweesh, 2017; Sonika, Harshaminder, Madhushankari, \& Sri Kennath, 2011; Tardivo et al., 2015; Viciano, Alemán, D'Anastasio, Capasso, \& Botella, 2011; Viciano, D'Anastasio, \& Capasso, 2015; Viciano, López-Lázaro, \& Alemán, 2013; Yong et al., 2018; Zorba, Moraitis, Eliopoulos, \& Spiliopoulou, 2012; Zorba, Moraitis, \& Manolis, 2011; Zorba, Vanna, \& Moraitis, 2014) and deciduous teeth (López-Lázaro, Alemán, Viciano, Irurita, \& Botella, 2018; Paknahad, Vossoughi, \& Ahmadi Zeydabadi, 2016; Shankar et al., 2013; Singh, Bhatia, Sood, \& Sharma, 2017; Viciano et al., 2013; Ządzińska, Karasińska, JedrychowskaDańska, Watala, \& Witas, 2008).

Although the deciduous dentition shows significant sexual dimorphism (De Vito \& Saunders, 1990; Viciano et al., 2013), its application for sex estimation in nonadult individuals has been relatively limited, for three main reasons: (a) the low levels of minerals in the deciduous dentition mean that it is frequently in a worse state of conservation in comparison to the permanent dentition (De Menezes Oliveira et al., 2010; Wilson \& Beynon, 1989); (b) the early age at which the deciduous teeth exfoliate means that they are recovered less frequently (Hillson, 1996); and (c) the typical small sample size of deciduous teeth in osteological collections significantly reduces the statistical power required for the development of reliable sex diagnosis methods (GarciaGodoy, Michelen, \& Townsend, 1985; Ządzińska et al., 2008).

On the basis of these limitations, odontometric techniques for sex estimation developed on the permanent dentition might be applied not only to adult individuals, but also to nonadult individuals. As the permanent teeth develop early and remain unchanged throughout life once they have formed (except in cases where specific changes and disorders of function, pathology or nutrition have an effect on the normal size of teeth), any effects on sexual dimorphism in the permanent teeth that can be observed in adults should also apply to nonadult individuals (Cardoso, 2008). Thus, to estimate sex using odontometrics, the permanent dentition from adult individuals can be used to develop the equations, which can then be applied to the permanent dentition of nonadult individuals. This methodology has been used with satisfactory results (Aris, Nystrom, \& Craig-Atkins, 2018; Beyer-Olsen \& Alexandersen, 1995; Okazaki, 2005; Rösing, 1983; Thompson, 2013; Viciano et al., 2011, 2015). However, all of these studies except Aris et al. (2018) were carried out using skeletal samples of archeological origins. Here the biological sex of the adult and/or nonadult individuals was unknown, and the sex was previously estimated by descriptive methods using pelvic and/or cranial features. Therefore, in these studies there remains uncertainty of the reliability of the skeletal sex estimation, as it first depends on the integrity and state of preservation of the bone remains. The reliability of the odontometric technique developed using the sample of adult individuals is thus may have been compromised. Moreover, as the biological sex of the nonadult individuals is not known, reliable comparisons with the estimated odontometric sex cannot be made to establish the rate of correct sex assignment. In contrast, Aris et al. (2018) used an osteological collection of identified adult and nonadult individuals to develop the odontometric technique for sex estimation. However, their study was limited to the analysis of only the maxillary first molar, which greatly reduces the applicability of the odontometric technique when other teeth are available.

With this background, the present study aimed to evaluate the complete permanent dentition of an identified osteological collection to develop an odontometric technique for sex estimation, and evaluate its applicability and reliability for sex estimation of nonadult individuals.

\section{2 | MATERIALS AND METHODS}

\section{1 | Study sample}

This study was based on the identified human skeletal collection of the Certosa Cemetery (Bologna, Italy). These individuals are housed at the Museum of Anthropology of the Alma Mater Studiorum University of Bologna. Reliable antemortem information obtained from the cemetery archives and death certificates provided detailed data on 
their sex, place and date of birth and death, date of burial, occupation, and cause of death, among other information (Belcastro et al., 2017).

The study sample consisted of 132 individuals (70 males, 62 females). The age at death of these individuals was from 8 years to 87 years (mean age at death, $38.93 \pm 18.61$ years). Figure 1a shows the distribution by age at death and by sex of the sample. The deaths occurred during the six decades from 1898 to 1944 , with $82.6 \%$ of the deaths before 1933 , which means that this sample largely dates from the first third of the 20th century. Figure $1 \mathrm{~b}$ shows the distribution by decade of death. According to the ages at death, the individuals were divided into two age groups following conventional anthropological categories (modified from Vallois, 1960): nonadult individuals (from birth to 20 years), and adult individuals ( $\geq 21$ years).

The sample was divided into two subsamples: (a) the reference subsample, which comprised 106 adult individuals aged from 21 years to 87 years (53 males, 53 females); and (ii) the experimental subsample, which comprised 26 nonadult individuals aged from 8 years to 20 years (17 males, 9 females; Table 1). The reference subsample provided the odontometric data used for the binary logistic regression analysis. The equations calculated from these data were then applied to the experimental subsample to estimate the sex.

\subsection{Inclusion criteria and measurement procedure}

Prior to the collection of the different dental measurements, all of the teeth were examined for various limiting factors that might negatively affect the subsequent odontometric analysis. The limiting factors for exclusion from the analysis included: (a) pathological processes, such as caries, hypoplastic defects and traumatic injuries; (b) dental anomalies, such as anomalies in number, volume and shape; (c) taphonomic/ diagenetic effects; and (d) notably wear. For the crown measurements (see details below), the mesiodistal diameter was measured for the incisors to a maximum stage of 3 of incisal wear (according to Smith, 1984), and for the canines, premolars and molars to a maximum stage of 4 of incisal/occlusal wear. Buccolingual and diagonal crown diameters of the molars were taken for teeth to a maximum stage of 5 of occlusal wear.

After evaluation of the diverse limiting factors and exclusion of the measurements affected for each tooth examined, the crown and cervical measurements of the permanent dentition were collected. Four measurements were taken for incisors, canines and premolars, and eight measurements for molars, which for the "ideal" permanent dentition provided 88 measurements for both dental arches for each individual (i.e., those with all of the teeth present and without any limiting factors).

All of the measurements were taken with digital dental calipers (Masel Orthodontics Inc., USA) to an accuracy of $0.01 \mathrm{~mm}$. Measurements were taken on either the left or right side, depending on the tooth availability. If both contralateral teeth were available, the mean of the measurements were calculated. In the nonadult individuals in the experimental subsample, the measurements were only taken for the teeth that had a completely formed crown and showed initial root development. All of the crown and cervical measurements were taken according to the definitions of Hillson, FitzGerald, and Flinn (2005) (using the modifications outlined by Aubry, 2014), except for the mesiodistal cervical diameter, which was measured following the criteria of Vodanović, Demo, Njemirovskij, Keros, \& Brkić (2007). For the dental crown, the measurements collected were maximum (a)

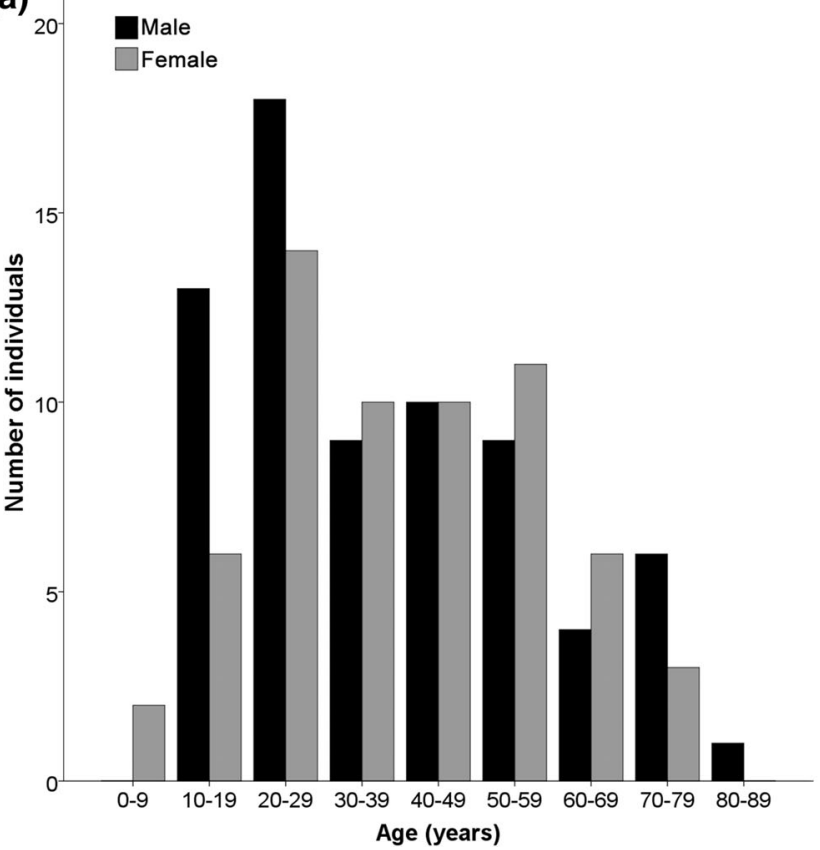

(b)

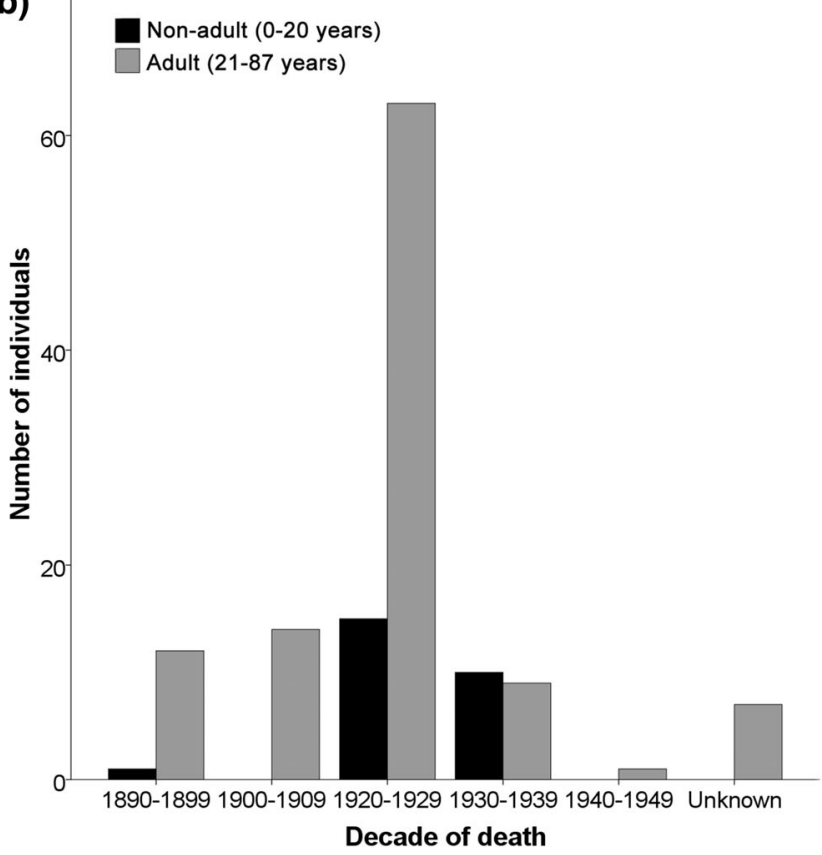

FIGURE 1 Distributions of the entire sample of 132 individuals by sex and age at death (a) and by decade of death (b) 
TAB LE 1 Distribution of the two subsamples (reference subsample and experimental subsample) according to sex and age group

\begin{tabular}{|c|c|c|c|c|c|c|c|}
\hline Subsample & \multicolumn{3}{|c|}{ Nonadult individuals } & \multicolumn{3}{|c|}{ Adult individuals } & TOTA \\
\hline \multicolumn{8}{|c|}{ Reference subsample } \\
\hline Male & 0 & 0 & 0 & 24 & 19 & 10 & 53 \\
\hline Female & 0 & 0 & 0 & 24 & 20 & 9 & 53 \\
\hline Subtotal & 0 & 0 & 0 & 48 & 39 & 19 & 106 \\
\hline Male & 0 & 2 & 15 & 0 & 0 & 0 & 17 \\
\hline Female & 0 & 2 & 7 & 0 & 0 & 0 & 9 \\
\hline Subtotal & 0 & 4 & 22 & 0 & 0 & 0 & 26 \\
\hline
\end{tabular}

Note: Modified from Vallois, 1960.

mesiodistal crown diameter (MDcrn), maximum buccolingual crown diameter (BLcrn), mesiobuccal-distolingual crown diameter (MBDLcrn), and mesiolingual-distobuccal crown diameter (MLDBcrn). At the level of the cement-enamel junction, the measurements collected were mesiodistal cervical diameter (MDcerv), buccolingual cervical diameter (BLcerv), mesiobuccal-distolingual cervical diameter (MBDLcerv), and mesiolingual-distobuccal cervical diameter (MLDBcerv). The further coding of the teeth defined them also as molar (M3/2/1), premolar (PM2/1), canine (C), or incisor (I2/1).

To evaluate the intraexaminer error, 25 randomly selected individuals from the original sample (17 adults, 8 nonadult individuals) were remeasured at different times by the principal examiner (J.V.; highly experienced in odontometrics). Moreover, to assess interexaminer error, a further 13 randomly selected individuals (8 adults, 5 nonadult individuals) were re-measured by a second examiner (C.T.; previous knowledge in dental morphology; trained in tooth measurements by the principal examiner over 3 months prior to the present study using a separate dental sample). In both situations, the same set of calipers was used, with a minimum period of 2 weeks and a maximum of 1 month between the two measurements. As both contralateral teeth were measured when present in these individuals, the numbers in Tables 2 and 3 do not represent the number of individuals studied, but rather the total number of teeth measured.

\section{3 | Statistical analysis}

Data were subjected to several statistical analyses using the statistical package for social sciences software IBM SPSS Statistics 22.0 (IBM Corp., 2013) for Windows.

The data were first assessed as the pooled samples for normality using Kolmogorov-Smirnov one-sample tests, and for homogeneity of variance using Levene tests, with $p \leq .05$ defining statistical significance. These analyses characterized the samples, allowed detection of any major errors in the database collection or in the data processing, and helped with the data distribution and homogeneity of variance.
This last information was necessary for acceptance/rejection of assumptions to apply later tests.

Before any statistical analysis was carried out, the differences between the means in all of the dimensions collected at the two different times were quantified to examine possible intraexaminer and interexaminer error. To determine the level of agreement between repeated measurements collected by the same examiner and by different examiners, the intraclass correlation coefficient (ICC) was calculated. The ICC is an index that reflects both the degree of correlation and the agreement between the measurements. As the ICC is a flexible statistical model that can be applied to many different circumstances, it comprises a total of 10 different variants (Koo \& Li, 2016; Perinetti, 2018). According to the nature of these data and the composition of the group of examiners, the ICC calculations were performed using the "two-way mixed-effects absolute-agreement" model, for both the intraexaminer and interexaminer errors. To determine the degree of agreement for a given set of data, the ICC calculated was compared to the criteria proposed by Koo and Li (2016), which establishes four levels of qualitative assessment: ICC $<0.5$ indicates "poor" reliability; ICC from 0.5 to 0.75 indicates "moderate" reliability; ICC from 0.75 to 0.9 indicates "good" reliability; and ICC >0.9 indicates "excellent" reliability.

Next, for both the reference and experimental subsamples, descriptive analysis was performed to calculate the sample size and the mean and standard deviation for each measurement. Measurements of the reference and experimental subsamples were tested using independent Student's $t$-tests (where normality and homoscedasticity were fulfilled) or nonparametric Mann-Whitney U-tests (for the other cases).

For the reference subsample, independent Student's $t$-tests were performed to explore potential significant differences between means of males and females when assumptions for normality and homoscedasticity were fulfilled ( $p>.05$ ), and nonparametric Mann-Whitney $U$-tests when they were not. As the multiple statistical tests were performed on the same dataset, the Bonferroni correction was applied to the $P$ estimates. Thus, the level of significance was set at $p=.05 / 88=.00057(p=.05 / N$, where $N$ represents the number of different variables tested). The magnitudes of the sexual differences 


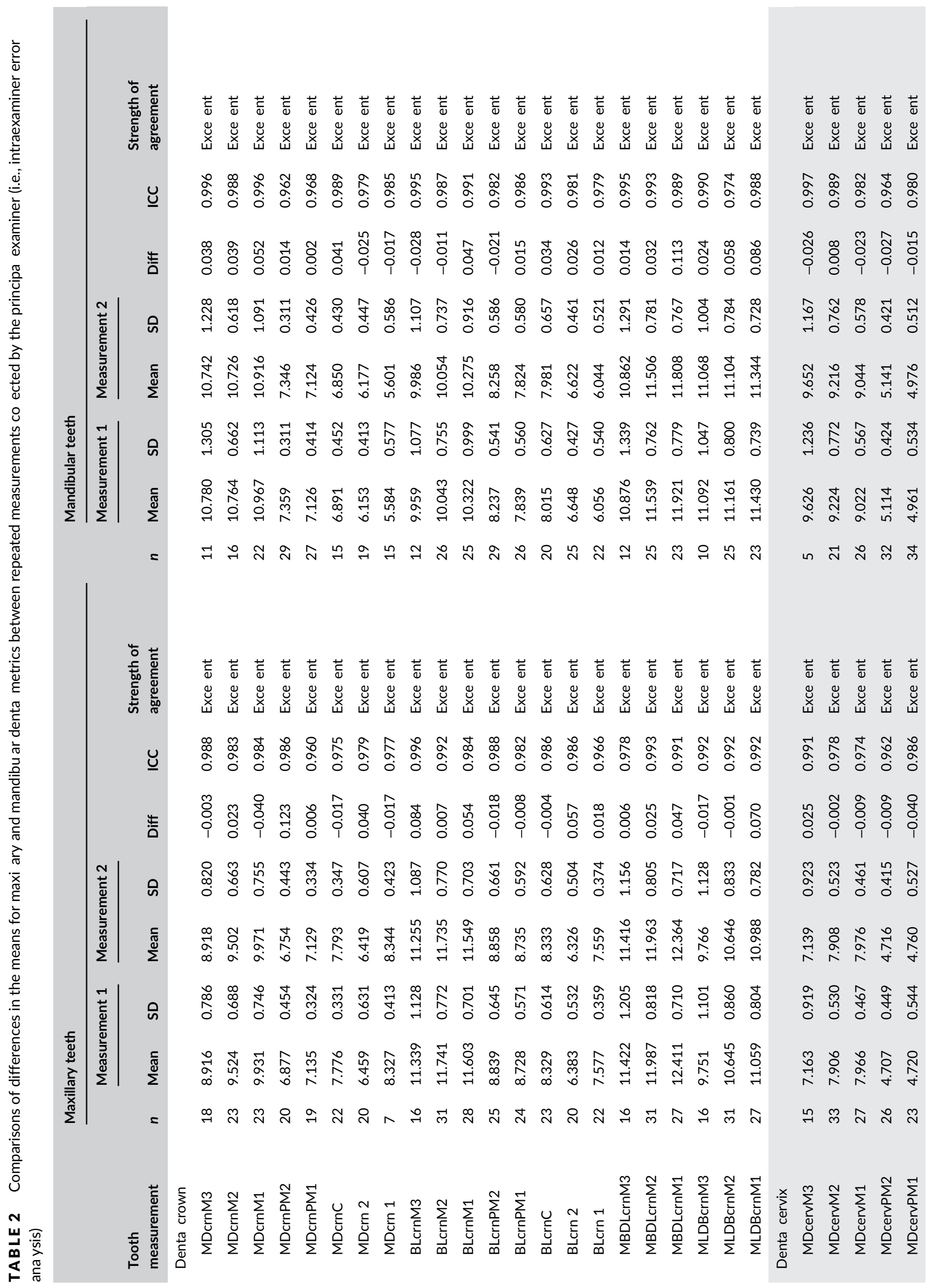




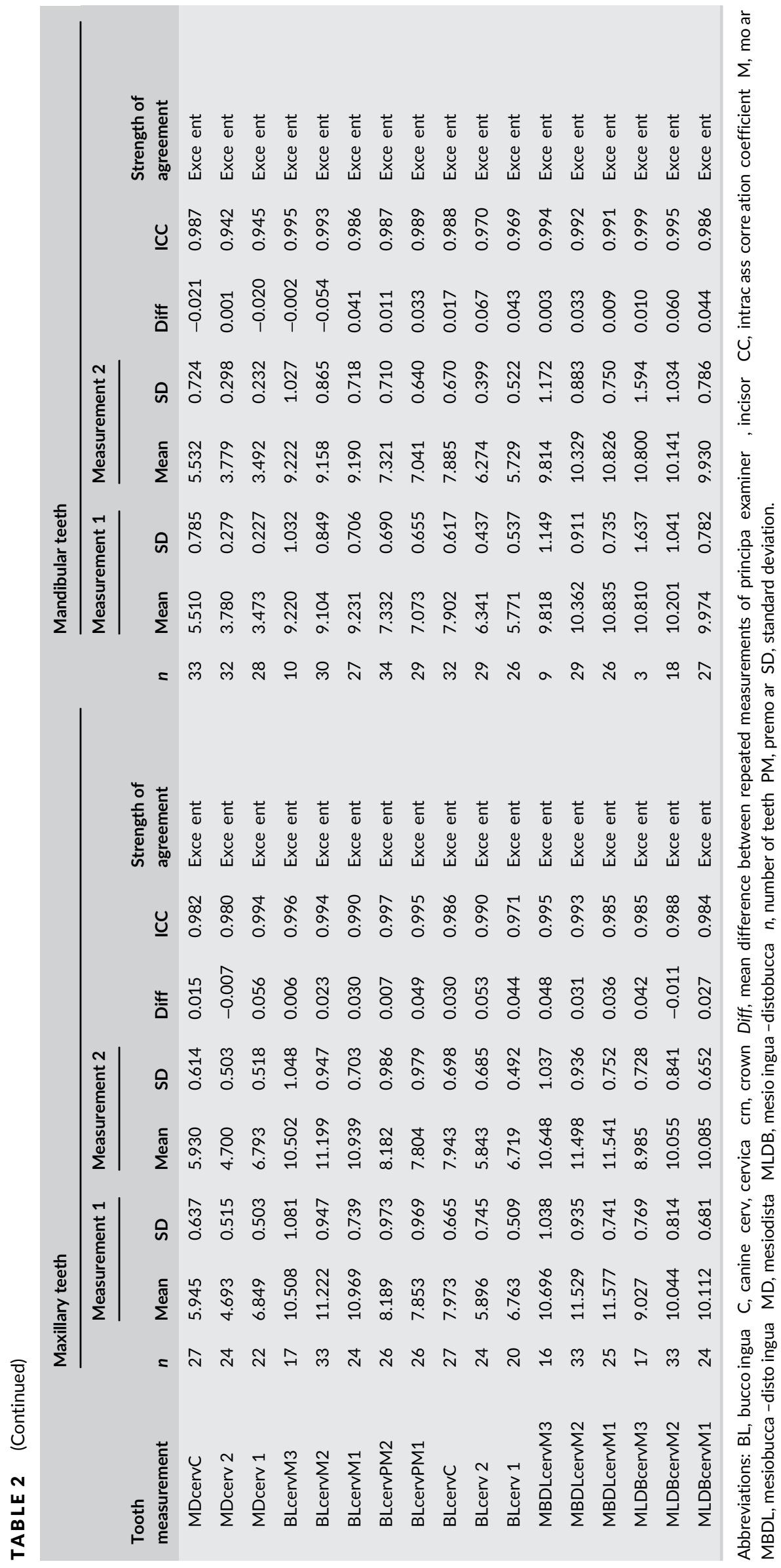




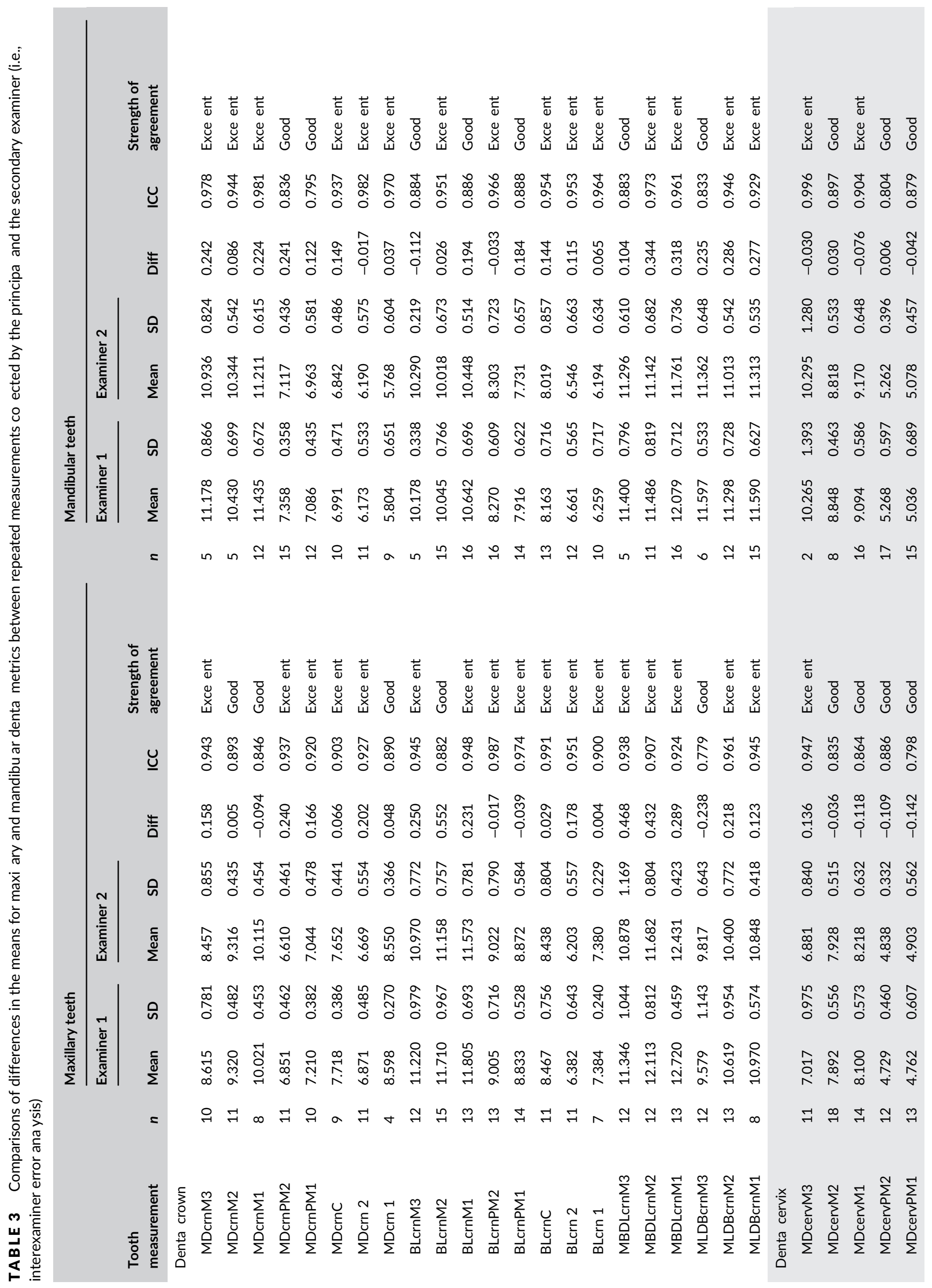




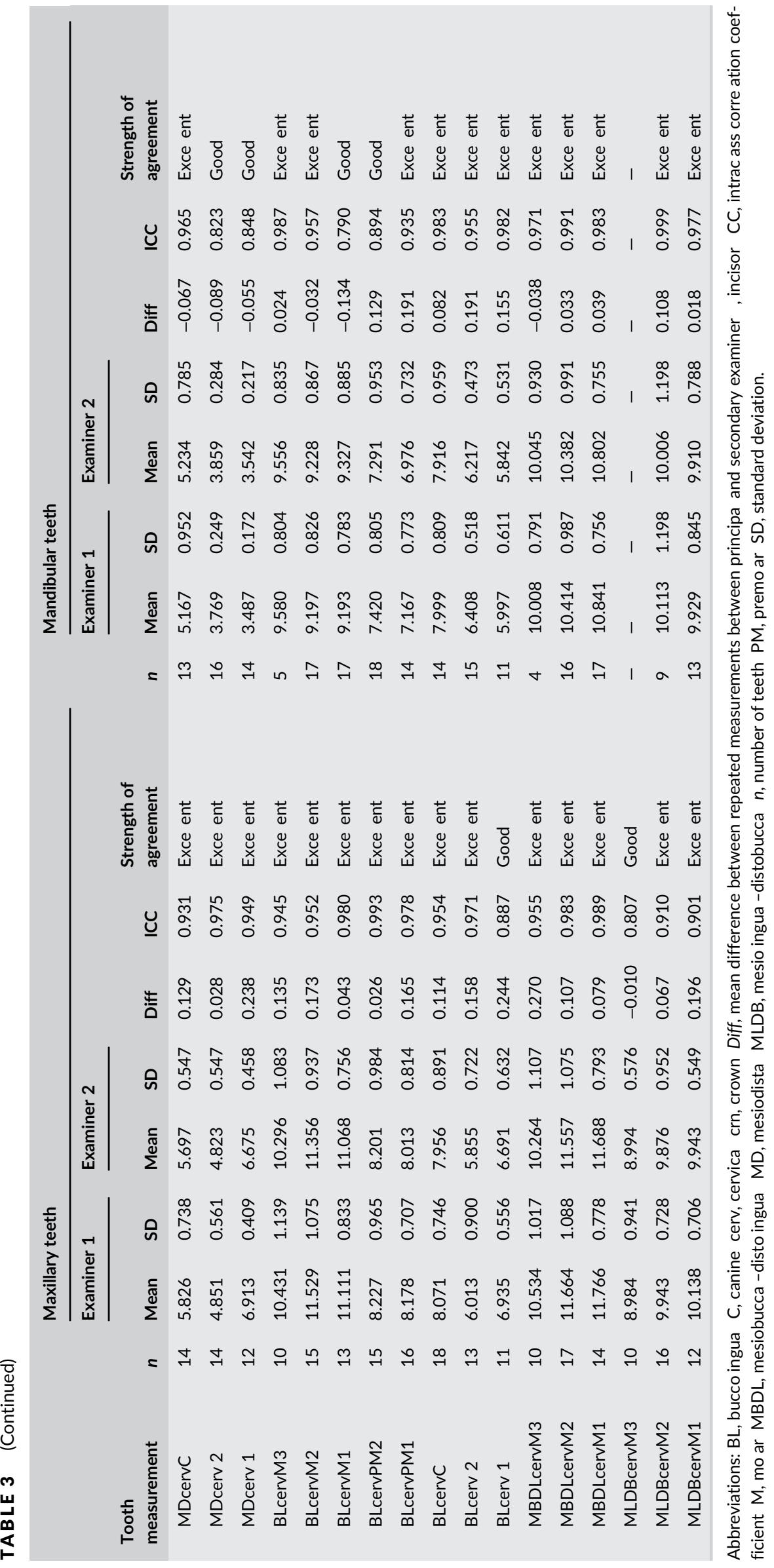


were also computed as indicators to describe the degree of differences between males and females, by calculation of the percentage of sexual dimorphism (\%SD) using the Equation (1), as given by Garn, Lewis, Swindler, and Kerewsky (1967):

$$
\% S D=\left(\begin{array}{ll}
\bar{X}_{m} & 1 \\
\bar{X}_{f} & 100
\end{array}\right.
$$

where $\bar{X}_{m}$ is the mean of the male tooth measurements and $\bar{X}_{f}$ is the mean of the female tooth measurements. A positive result indicates larger tooth size in males, and a negative result indicates larger tooth size in females. The dimorphic ranking was then tabulated for both dental arches by allotting the first rank to the measurements with the highest percentage of sexual dimorphism, and the last rank to the those with the lowest percentage.

Finally, binary logistic regression analyses were performed for the reference subsample to create a set of equations for sex discrimination. Separated binary logistic regression analyses were conducted for the maxillary and mandibular teeth. To maximize the applicability of the technique for forensic and archeological cases, the equations were calculated for a maximum combination of two measurements. Binary logistic regression analysis was performed instead of the commonly used discriminant function analysis for metric sex estimation methods, as the former is more robust and usually provides better analysis with more relaxed data requirements (Albanese, 2003; Pohar, Blas, \& Turk, 2004), and was therefore better suited to data in the present study. Binary logistic regression analysis produces coefficients for each measurement included in a model, as well as a constant. To use this information to estimate the sex of an individual, a logit $\left(L_{i}\right)$ must first be calculated according to Equation (2):

$$
L_{i}=\beta_{0}+\beta_{1} X_{1}+\beta_{2} X_{2}+\ldots+\beta_{n} X_{n}
$$

where $L_{i}$ is a linear function of the independent variable(s) $X_{n}, \beta_{0}$ is the constant, $\beta_{1}$ is the first coefficient, $X_{1}$ is the first measurement, and so on. Once $L_{i}$ is calculated, it can be used to calculate the probability of the female sex $\left(p_{f}\right)$ using Equation (3):

$$
p_{f}=\frac{1}{1+e^{-L_{i}}}
$$

The probability of male sex is simply $p_{m}=1 \quad p_{f}$. In practice, if $p_{f}$ is $>.5$, the individual is most likely to be female, whereas if $p_{f}$ is $<.5$, the individual is most likely to be male. In the present context, the closer $p_{f}$ is to 1 , the greater the probability that the individual is female, and the closer $p_{f}$ is to 0 , the greater the probability that the individual is male. When $p_{f}$ is close to the sectioning point of .5 , the probability of correct classification of an individual is lower, because this is the area of overlap between the two groups. To determine the fit of an equation to the data, a goodness-of-fit statistic was calculated, as the 2 log likelihood ( $2 \mathrm{LL}$ ). The $-2 \mathrm{LL}$ is a measure of how much unexplained information there is after the binary logistic regression equation has been fitted, whereby low values of $-2 \mathrm{LL}$ indicate better fitting to the equations.

\section{3 | RESULTS}

\subsection{Intraexaminer and interexaminer error analyses}

Following the selection criteria outlined above, the total number of teeth that comprised the random subsample for intraexaminer error analysis was 472 (225 maxillary, 247 mandibular), and the total number of teeth for the interexaminer error analysis was 278 (136 maxillary, 142 mandibular).

In the intraexaminer error analysis (Table 2), the maxillary and mandibular teeth generally showed similar ICCs. For the maxilla, the ICCs for the dental crown were 0.960-0.996 (i.e., with "excellent" agreement), with similar ICCs for the dental cervix, as 0.962-0.997 (i.e., "excellent"). For the mandible, the ICCs for the dental crown were 0.962-0.996 (i.e., "excellent"), with slightly lower ICCs for the dental cervix, as 0.942-0.999 (i.e., "excellent"). In addition, the differences between the means of the repeated measurements were $0.001-0.123 \mathrm{~mm}$ for the maxillary teeth, and $0.002-0.113 \mathrm{~mm}$ for the mandibular teeth.

For the interexaminer error analysis (Table 3), for the maxilla, the ICCs for the dental crown were 0.779-0.991 (i.e., "good" to "excellent"), with slightly higher ICCs for the dental cervix, as 0.798-0.993 (i.e., "good" to "excellent"). The data were similar for the mandible, where the ICCs for the dental crown were 0.795-0.982 (i.e., "good" to "excellent"), with slightly higher ICCs for the dental cervix, as 0.790-0.999 (i.e., "good" to "excellent"). The differences between the means of the repeated measurements were from 0.004 to $0.552 \mathrm{~mm}$ for the maxillary teeth, and from 0.006 to $0.344 \mathrm{~mm}$ for the mandibular teeth. In the interexaminer analysis, the ICC for the mesiolingualdistobuccal cervical diameter for the third maxillary molar could not be calculated, as it was not possible to take this measurement in these randomly selected individuals.

\section{2 | Differences between adult and nonadult individuals}

The data from the Student's $t$-tests and Mann-Whitney U-tests did not define any statistically significant differences between the means of the reference subsample and the experimental subsample across all of the 88 measurements $(p>.05)$, as 44 for the maxillary teeth and 44 for the mandibular teeth (Table 4).

\section{3 | Univariate sexual dimorphism}

Table 5 gives the data for the percentages of sexual dimorphism for each dental measurement for the reference subsample, together with 


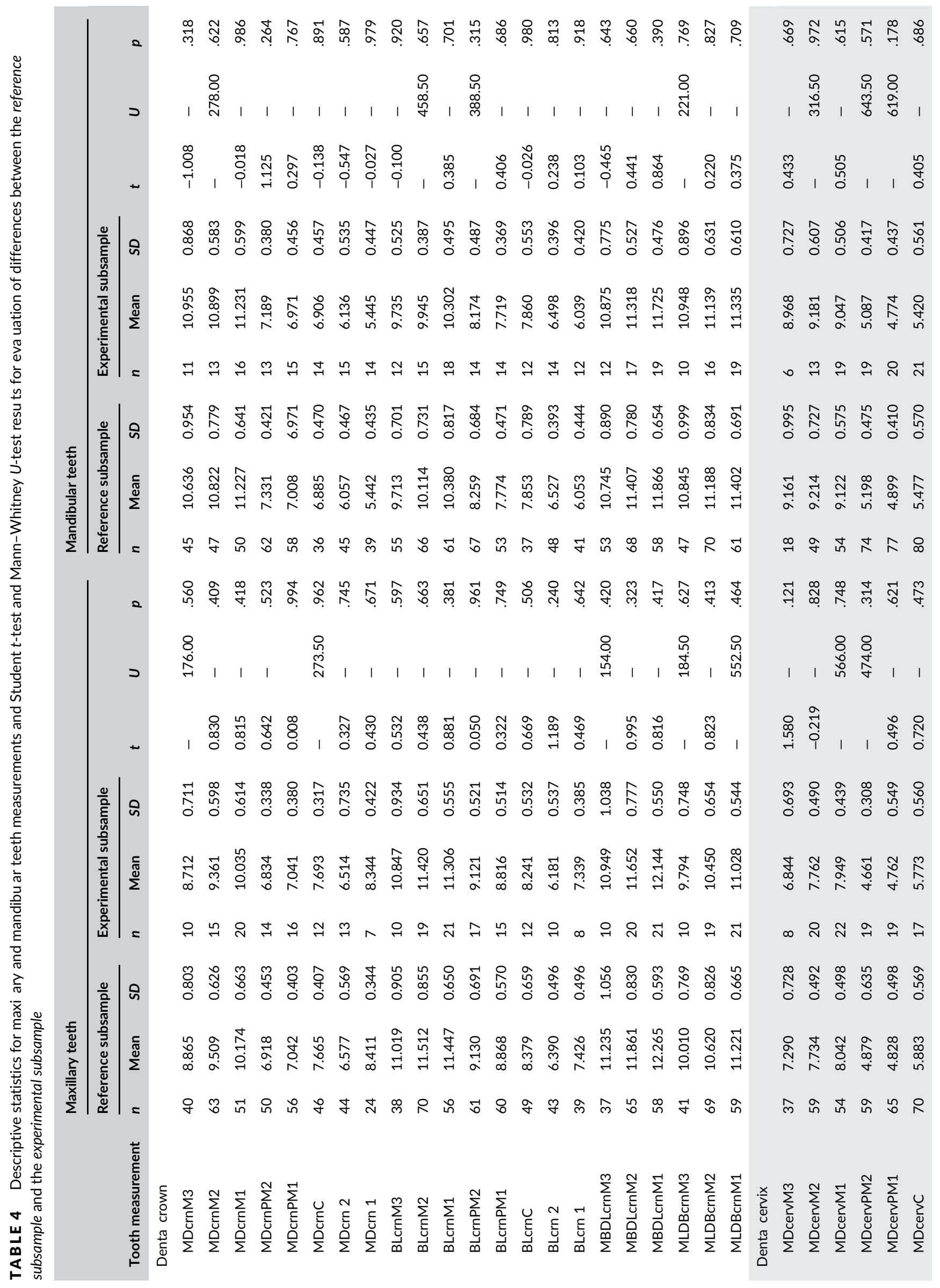




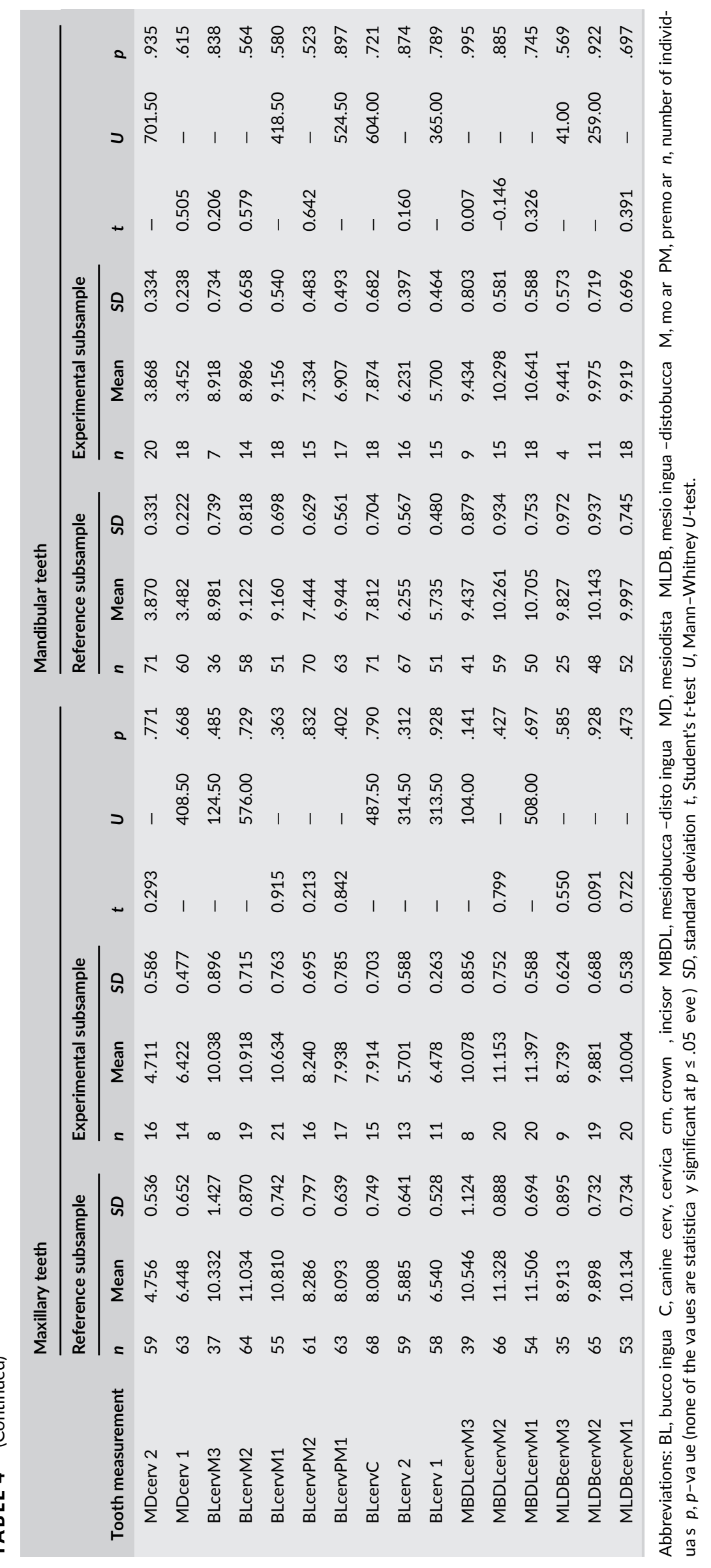




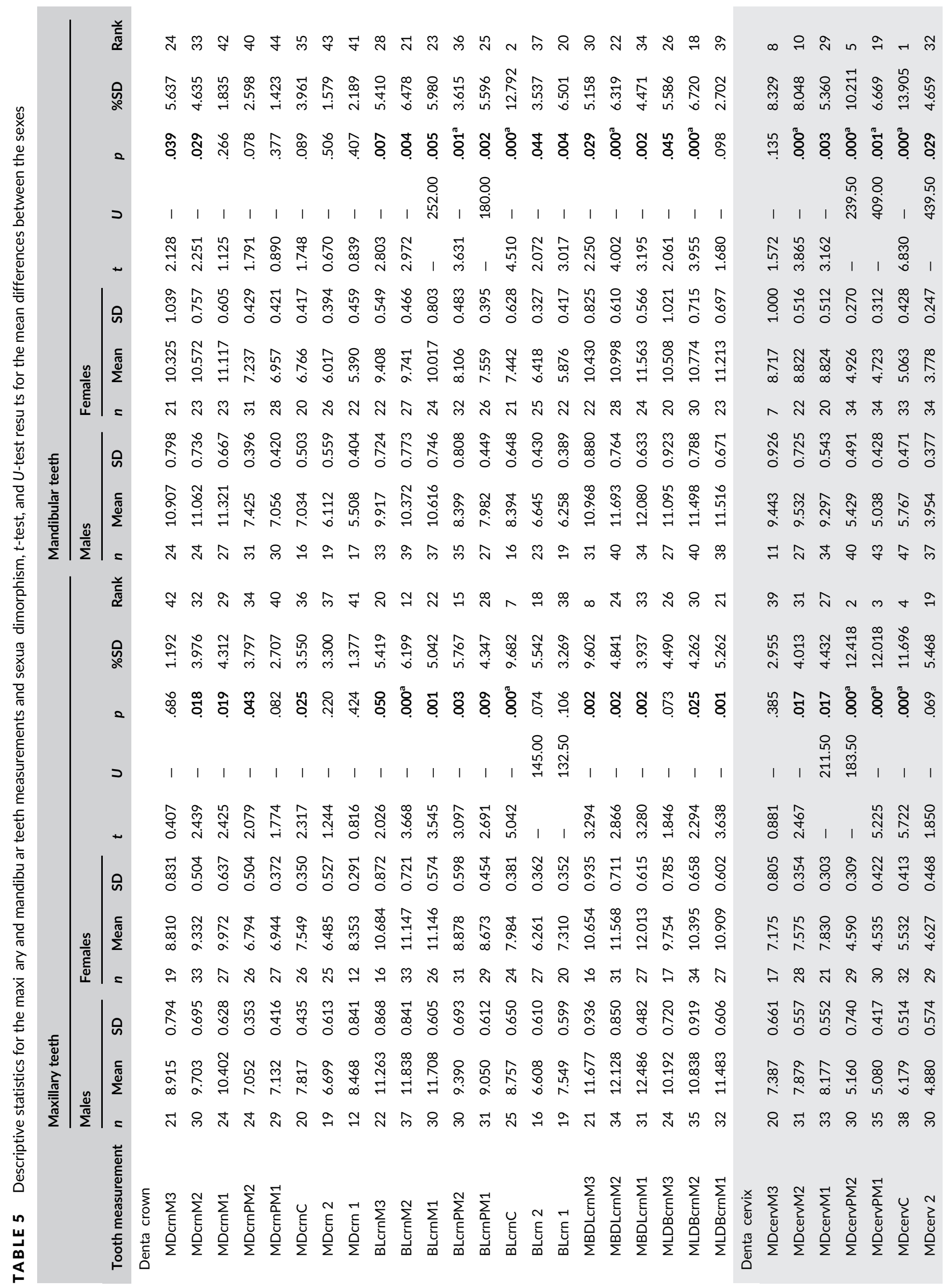




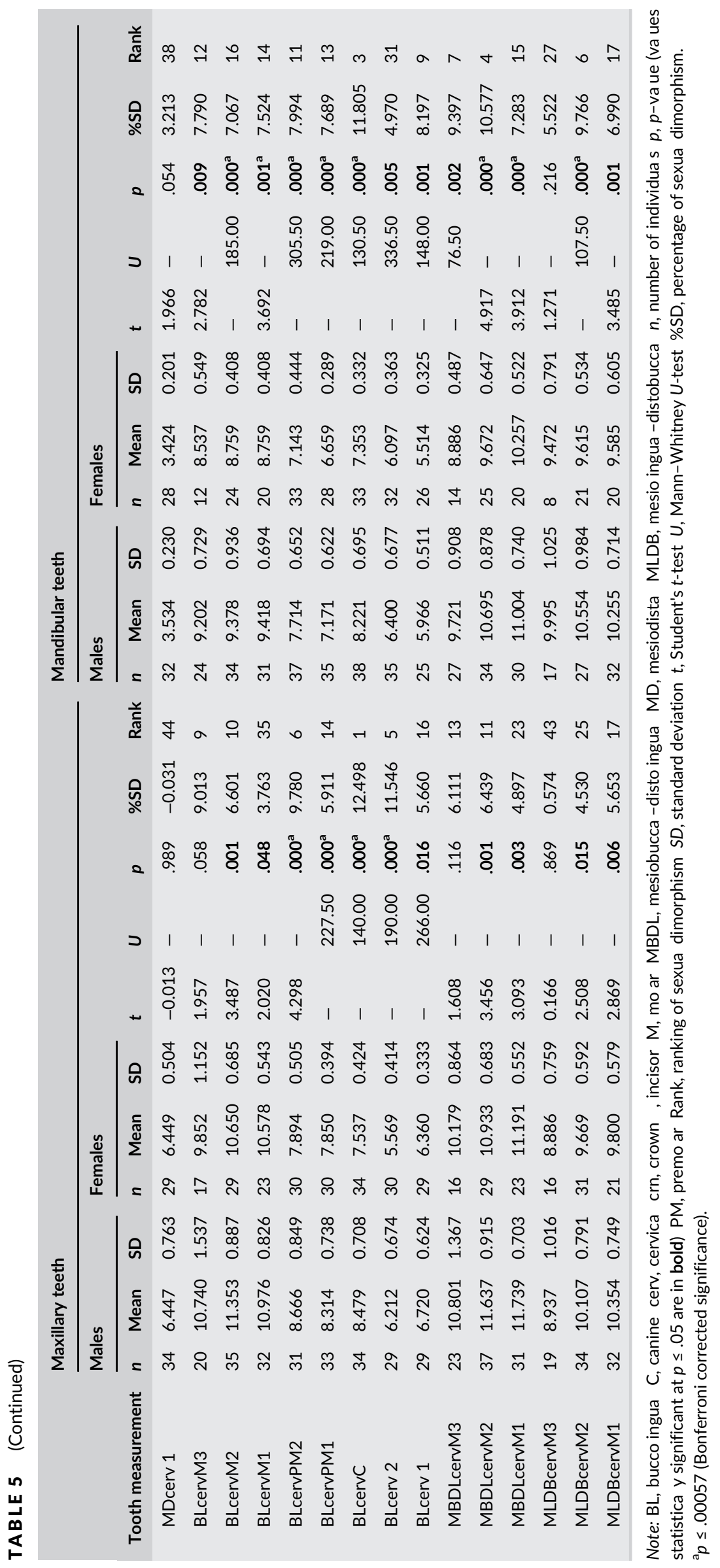


the rankings according to magnitude, for both of the dental arches. These percentages of sexual dimorphism ranged from $0.03-12.50 \%$ for the maxillary teeth, and from $1.42-13.91 \%$ for the mandibular teeth (negative values indicate that means for females exceeded those for males, positive values show the reverse). The buccolingual cervical diameter of the canine (BLcervC') showed the greatest sexual dimorphism for the maxillary dentition, whereas the mesiodistal cervical diameter of the canine (MDcervC,) showed the greatest sexual dimorphism for the mandibular dentition.

Considering all of the measurements pooled by tooth and calculation of the mean, the greatest percentage of sexual dimorphism in the maxilla was shown by the canine ( $C^{\prime} ; \% \mathrm{SD}_{\text {mean }}=9.36 \%$ ), followed by the second premolar $\left(\mathrm{PM}^{2} ; \% \mathrm{SD}_{\text {mean }}=7.94 \%\right)$, the lateral incisor $\left(\mathrm{I}^{2} ; \%\right.$ $\left.\mathrm{SD}_{\text {mean }}=6.46 \%\right)$, and the first premolar $\left(\mathrm{PM}^{1} ; \% \mathrm{SD}_{\text {mean }}=6.25 \%\right)$. For the mandible, the greatest percentage of sexual dimorphism was shown by the canine $\left(\mathrm{C}, \%\right.$ SD $\left.\mathrm{S}_{\text {mean }}=10.62 \%\right)$, followed by the second $\operatorname{molar}\left(\mathrm{M}_{2} ; \% \mathrm{SD}_{\text {mean }}=7.45 \%\right)$, the third molar $\left(\mathrm{M}_{3} ; \% \mathrm{SD}_{\text {mean }}=6.60 \%\right)$ and the second premolar $\left(\mathrm{PM}_{2} ; \% \mathrm{SD}_{\text {mean }}=6.11 \%\right)$. In addition, it should be emphasized that the measurements collected at the cervical level showed higher percentage of sexual dimorphism than those collected at the level of the dental crown $\left(\% \mathrm{SD}_{\text {mean }}=7.25 \%\right.$ vs. $4.70 \%$; for all maxillary and mandibular measurements pooled).

Table 5 also shows the sample sizes, means and standard deviations, $t$-value, $U$-value and the degree of significance of the differences between the males and females for all of the dental measurements for the reference subsample. In the maxilla, 31 of the 44 measurements collected showed higher means in the males compared to the females, and in the mandible, 34 of the 44 measurements showed higher means in the males compared to the females. These differences were statistically significant at $p \leq .05$, and 25 of them (maxilla, 9; mandible, 16) were significant after Bonferroni correction, at $p \leq .00057$ (see Section 2.3 for details). There were no significant differences in the crown diameters of the maxillary central and lateral incisors (i.e., $\mathrm{MDCrnI}^{1}, \mathrm{BLCrnl}^{1}, \mathrm{MDCrnl}^{2}, \mathrm{BLCrnl}^{2}$ ), and in any analyzed diameter at the cervical level of the maxillary third molar (i.e., $\mathrm{MDcervM}^{3}$, BLcervM ${ }^{3}, \mathrm{MBDLcervM}^{3}, \mathrm{MLDBcervM}^{3}$ ). There was one measurement $\left(\mathrm{MDcervl}^{1}\right)$ that showed females with higher values than males, but this did not reach statistical significance.

Considering the dentition as a whole, the most sexually dimorphic teeth that showed statistical significance were the canines in both maxilla and mandible ( $C^{\prime}, C$,), as represented by the mesiodistal and buccolingual diameters of the crown and cervix, followed by the mandibular second molar $\left(M_{2}\right)$, represented by the mesiodistal, buccolingual and diagonal diameters of the crown and cervix. Next came the maxillary and mandibular second premolars $\left(\mathrm{PM}^{2}, \mathrm{PM}_{2}\right)$, the maxillary and mandibular first premolars $\left(\mathrm{PM}^{1}, \mathrm{PM}_{1}\right)$ and the mandibular first molar $\left(\mathrm{M}_{1}\right)$.

\subsection{Binary logistic regression analysis}

The logit equations and their allocation accuracies are given in Table 6. Equations with a discriminant power $<80 \%$ were excluded, and only the logit equations in which a minimum of 30 cases were used for their construction are shown.

It can be seen here that the correct allocation accuracy was from 80.0 to $100 \%$ in the females, and from 80.0 to $95.0 \%$ in the males. Therefore, the females were classified more accurately than the males for all of the logit equations. For the pooled sexes, the overall correct allocation accuracy was from 80.4 to $94.9 \%$. Moreover, the correct allocation accuracy provided by the different logit equations was a little lower for the maxillary teeth (80.4-88.9\%) than for the mandibular teeth (80.9-94.9\%).

When the 40 logit equations obtained were analyzed together, this showed that the canine was the best predictor of sex in this sample, as this appeared in 33 of the 40 logit equations (maxillary teeth, 8/11; mandibular teeth, 25/29). Two of these logit equations are a combination of measurements from the same canine (i.e., $L_{3}, L_{4}$ ), while the remaining are a combination of the canine with measurements from other teeth (i.e., $L_{2}, L_{5}-L_{9}, L_{12}-$ $L_{36}$ ). On the other hand, it should be emphasized that the dental cervical region was a good predictor of sex. Eighteen of the logit equations use only cervical measurements, compared with 22 equations that used a cervical measurement in combination with a crown measurement.

The following example illustrates briefly the methodological procedure used here to calculate and interpret the logit equations developed. In a hypothetical forensic/archeological case to estimate the sex of a skeletal individual, only a maxillary canine was recovered that showed moderate/severe incisal wear. As a result, only the mesiodistal and buccolingual cervical diameters could be measured. The mesiodistal cervical diameter was $6.17 \mathrm{~mm}$, and the buccolingual cervical diameter was $8.36 \mathrm{~mm}$. The sex can be estimated if logit equation $L_{4}$ listed in Table 6 is applied, as follows:

$$
L_{4}=30.205-1.797(6.17)-2.494(8.36)=-1.73233
$$

The result of 1.73233 can be input into the following Equation (5) to calculate the probability of female sex $\left(p_{f}\right)$ :

$$
p_{f}=\frac{1}{1+e^{-(-1.73233)}}=.15029
$$

This value is below the sectioning point of .5 ; thus, the $p_{f}$ value indicates that there is a $15.03 \%$ probability that the individual is female. Therefore, there is an $84.97 \%$ probability that the individual is male $\left(p_{m}=1 \quad p_{f}=1 \quad .15029=.84971\right)$.

\section{5 | Odontometric sex estimation of nonadult remains}

The set of logit equations created from the reference subsample was then applied to the available permanent dentition of the nonadult individuals of the same population (i.e., experimental subsample) to estimate the sex. As the multiple logit equations were often applied to 
TABLE 6

Binary logistic regression equations and assessment of the fit of each logit equation ${ }^{a}$

\begin{tabular}{|c|c|c|c|c|c|c|c|c|}
\hline \multirow[b]{2}{*}{ Dentition } & \multirow[b]{2}{*}{ Logit equation $^{b}$} & \multirow[b]{2}{*}{$N$} & \multirow[b]{2}{*}{$-2 L L$} & \multicolumn{2}{|c|}{ Female correct } & \multicolumn{2}{|c|}{ Male correct } & \multirow[b]{2}{*}{ Total } \\
\hline & & & & $n / N$ & $\%$ & $n / N$ & $\%$ & \\
\hline \multicolumn{9}{|l|}{ Maxillary teeth } \\
\hline Lateral incisor canine & $\mathrm{L}_{2} \quad 23.192+1.979\left(\mathrm{MDcerv}^{2}\right)$ & 45 & 29.787 & $24 / 25$ & 96.0 & $16 / 20$ & 80.0 & 88.9 \\
\hline \multirow[t]{2}{*}{ Canine first premolar } & $\begin{array}{l}\mathrm{L}_{5} \quad 27.983 \quad 4.671\left(\mathrm{MDcervC}^{\prime}\right) \\
\left(\mathrm{MDcrnPM}^{1}\right)\end{array}$ & 43 & 34.383 & $19 / 22$ & 86.4 & $17 / 21$ & 81.0 & 83.7 \\
\hline & $\mathrm{L}_{6} \quad 33.920 \quad 3.763$ (MDcervC') & 50 & 39.340 & $20 / 24$ & 83.3 & $21 / 26$ & 80.8 & 82.0 \\
\hline Canine second premolar & $\begin{array}{l}\mathrm{L}_{7} \quad 37.979 \quad 4.997\left(\mathrm{MDcerv}^{\prime}\right) \\
\quad\left(\mathrm{MDcrnPM}^{2}\right)\end{array}$ & 43 & 26.533 & $21 / 23$ & 91.3 & $17 / 20$ & 85.0 & 88.4 \\
\hline First premolar & $\begin{array}{l}\mathrm{L}_{10} \quad 15.773+0.108\left(\mathrm{BLcrnPM}^{1}\right) \quad 3.456 \\
\quad\left(\mathrm{MDcervPM}^{1}\right)\end{array}$ & 52 & 51.245 & $22 / 26$ & 84.6 & $21 / 26$ & 80.8 & 82.7 \\
\hline $\begin{array}{l}\text { Second premolar second } \\
\text { molar }\end{array}$ & $\begin{array}{l}\mathrm{L}_{11} \quad 38.713 \quad 0.382\left(\mathrm{BLCrnPM}^{2}\right) \\
\quad\left(\mathrm{MBDLcervM}^{2}\right)\end{array}$ & 45 & 37.600 & $18 / 22$ & 81.8 & $20 / 23$ & 87.0 & 84.4 \\
\hline \multicolumn{9}{|l|}{ Mandibular teeth } \\
\hline \multirow[t]{3}{*}{ Central incisor canine } & $\mathrm{L}_{12} \quad 26.362+1.737\left(\right.$ MDcervl $\left._{1}\right) \quad 4.176$ (BLcervC, $)$ & 50 & 39.396 & $24 / 25$ & 96.0 & $21 / 25$ & 84.0 & 90.0 \\
\hline & $\mathrm{L}_{13} \quad 29.124 \quad 1.199$ (BLcervl $\left._{1}\right) \quad$ 4.113(MDcervC,) & 47 & 35.145 & $19 / 23$ & 82.6 & $20 / 24$ & 83.3 & 83.0 \\
\hline & $\mathrm{L}_{14} \quad 54.844+3.282\left(\right.$ BLcervl $\left._{1}\right)$ & 44 & 25.269 & $22 / 24$ & 91.7 & $17 / 20$ & 85.0 & 88.6 \\
\hline Lateral incisor canine & $\mathrm{L}_{15} \quad 20.509+1.275\left(\mathrm{MDcrnl}_{2}\right) \quad$ 5.157(MDcervC, $)$ & 41 & 30.188 & $19 / 22$ & 86.4 & $16 / 19$ & 84.2 & 85.4 \\
\hline \multirow[t]{5}{*}{ Canine first premolar } & 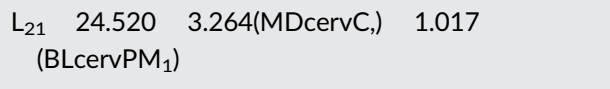 & 58 & 44.933 & $22 / 27$ & 81.5 & $25 / 31$ & 80.6 & 81.0 \\
\hline & $\begin{array}{l}\mathrm{L}_{22} 27.0915 .229(\mathrm{BLcervC},)+1.874 \\
\quad\left(\mathrm{MDcrnPM}_{1}\right)\end{array}$ & 47 & 35.207 & $23 / 24$ & 95.8 & $19 / 23$ & 82.6 & 89.4 \\
\hline & $\begin{array}{l}\mathrm{L}_{23} \quad 67.561 \quad 13.020\left(\mathrm{BL}_{\text {Lerv }} \mathrm{C},\right)+4.267 \\
\quad\left(\mathrm{BLcrnPM}_{1}\right)\end{array}$ & 44 & 14.681 & $22 / 23$ & 95.7 & $19 / 21$ & 90.5 & 93.2 \\
\hline & 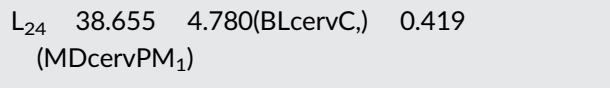 & 61 & 44.926 & $25 / 29$ & 86.2 & $27 / 32$ & 84.4 & 85.2 \\
\hline & $\begin{array}{l}\mathrm{L}_{25} \quad 42.0367 .321(\mathrm{BLcervC},)+2.074 \\
\quad\left(\mathrm{BLcervPM}_{1}\right)\end{array}$ & 56 & 32.643 & $23 / 26$ & 88.5 & $25 / 30$ & 83.3 & 85.7 \\
\hline \multirow[t]{4}{*}{ Canine second premolar } & $\begin{array}{l}\mathrm{L}_{26} \quad 26.776 \quad 4.861(\mathrm{BLcervC},)+1.472 \\
\quad\left(\mathrm{MDcrnPM}_{2}\right)\end{array}$ & 49 & 36.115 & $23 / 25$ & 92.0 & $20 / 24$ & 83.3 & 87.8 \\
\hline & $\mathrm{L}_{27} \quad 23.240 \quad 6.642\left(\mathrm{BLcervC}_{,}\right)+3.409\left(\mathrm{BLcrnPM}_{2}\right)$ & 54 & 32.975 & $25 / 26$ & 96.2 & $25 / 28$ & 89.3 & 92.6 \\
\hline & $\begin{array}{l}\mathrm{L}_{28} \quad 38.013 \quad 3.313(\mathrm{BLcervC},) \quad 2.451 \\
\quad\left(\mathrm{MDcervPM}_{2}\right)\end{array}$ & 59 & 42.830 & $26 / 29$ & 89.7 & $24 / 30$ & 80.0 & 84.7 \\
\hline & $\begin{array}{l}\mathrm{L}_{29} \quad 30.9175 .234(\mathrm{BLcervC},)+1.275 \\
\quad\left(\mathrm{BLcervPM}_{2}\right)\end{array}$ & 59 & 44.744 & $25 / 27$ & 92.6 & $26 / 32$ & 81.3 & 86.4 \\
\hline \multirow[t]{2}{*}{ Canine second molar } & $\begin{array}{l}\mathrm{L}_{30} \quad 27.206 \quad 3.618(\text { MDcervC, }) \\
\quad\left(B L c e r v M_{2}\right)\end{array}$ & 49 & 38.198 & $16 / 20$ & 80.0 & $26 / 29$ & 89.7 & 85.7 \\
\hline & 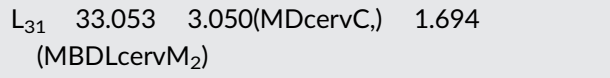 & 47 & 34.183 & $16 / 19$ & 84.2 & $23 / 28$ & 82.1 & 83.0 \\
\hline
\end{tabular}


TABLE 6 (Continued)

\begin{tabular}{|c|c|c|c|c|c|c|c|c|c|}
\hline Dentition & & & \multirow{2}{*}{$\begin{array}{l}N \\
47\end{array}$} & \multirow{2}{*}{$\begin{array}{l}-2 \mathrm{LL} \\
34.319\end{array}$} & \multicolumn{2}{|c|}{ Female correct } & \multicolumn{2}{|c|}{ Male correct } & \multirow{2}{*}{$\begin{array}{l}\text { Total } \\
80.9\end{array}$} \\
\hline & $\begin{array}{l}\mathrm{L}_{32} 41.9795 .415 \text { (BLcervC,) } \\
\left(\mathrm{MLDBcrnM}_{2}\right)\end{array}$ & 0.051 & & & $17 / 21$ & 81.0 & $21 / 26$ & 80.8 & \\
\hline & $\begin{array}{l}\mathrm{L}_{33} \quad 61.962 \quad 6.393(\text { BLcervC,) } \\
\left(\mathrm{MBDLcervM}_{2}\right)\end{array}$ & 1.296 & 42 & 25.485 & $16 / 18$ & 88.9 & $21 / 23$ & 87.5 & 88.1 \\
\hline \multirow{2}{*}{ Canine third molar } & 3.716(BLcervC,) & $0.385\left(B_{L} \mathrm{crnM}_{3}\right)$ & 39 & 31.930 & $17 / 18$ & 94.4 & $18 / 21$ & 85.7 & 89.7 \\
\hline & $\begin{array}{l}\mathrm{L}_{36} \quad 33.364 \quad 4.553(\mathrm{BLcervC})+\mathrm{C} \\
\quad\left(\mathrm{MBDLcrnM} \mathrm{M}_{3}\right)\end{array}$ & 0.163 & 39 & 29.506 & $19 / 19$ & 100.0 & $17 / 20$ & 85.0 & 92.3 \\
\hline $\begin{array}{l}\text { Second premolar second } \\
\text { molar }\end{array}$ & $\begin{array}{l}\mathrm{L}_{37} 21.490+0.083\left(\mathrm{BLcrnPM}_{2}\right) \\
\quad\left(\mathrm{MBDLcervM}_{2}\right)\end{array}$ & 2.189 & 42 & 38.827 & $16 / 19$ & 84.2 & $21 / 23$ & 91.3 & 88.1 \\
\hline Second molar & $\begin{array}{ccc}\mathrm{L}_{40} & 22.520 & 0.055\left(\mathrm{MLDBcrnM}_{2}\right. \\
\left(\mathrm{MBDLcervM}_{2}\right)\end{array}$ & 2) 2.173 & 57 & 53.525 & $20 / 25$ & 80.0 & $29 / 32$ & 90.6 & 86.0 \\
\hline
\end{tabular}

Abbreviations: 2LL, 2 log likelihood value; $n$, indicates the number of individuals correctly classified compared with the total of individuals used for the classification; $N$, indicates the total number of individuals used to develop the logit equations.

${ }^{a}$ Only logit equations with minimum of 30 cases were used for their construction, and only those with correct allocation rates $>80 \%$ are presented.

bee Section 3.4 for example of application of a binary logistic regression equation to estimate sex.

a single individual, the following criteria were implemented to deal with conflicting sex estimates. The sex was assigned when one of the following criterions was met, while if none of them were met, the sex was assigned as uncertain:

Criterion 1. One or more estimates of the same group without any other conflicting estimates, with at least one estimate with a probability of group membership $\geq 80 \%$.

Criterion 2. A probability of group membership for any estimate $\geq 90 \%$, and a probability of group membership for any conflicting estimate $\leq 85 \%$

Criterion 3. The number of estimates for a given group with a probability of membership $\geq 80 \%$ was $\geq 50 \%$ higher than the conflicting estimates (i.e., the number of estimates for a given group with a probability of membership $\geq 80 \%$ is more than twice the conflicting estimates).

Table S1 shows the complete results for the sex assignment of each individual based on the odontometric analysis. Table 7 summarizes the data for the sex estimation for each nonadult individual, along with the comparisons with the known biological sex.

Sex was assigned for 22 of the 26 nonadult individuals using odontometrics (Figure 2). This represents an applicability rate of $84.6 \%$ of the individuals. Within these 22 nonadult individuals, 12 were classified as male (54.5\%; aged $14-20$ years) and 10 as female (45.5\%; aged 8-20 years). For four nonadult individuals (15.4\%; individuals 024F, 039M, 081M, 142M; aged between 9 and 15 years; Table 7), it was possible to collect several measurements of their available teeth, but sex could not be assigned as none of the logit equations developed in this study could be applied.

Comparison of the sex of the 22 nonadult individuals estimated by odontometrics with the known biological sex showed matches in 20 cases $(90.9 \%)$, and mismatches in two cases (9.1\%).

\section{4 | DISCUSSION}

Overall, dental measurements that showed the greatest percentages of sexual dimorphism clearly tended to show statistically significant differences between the two sexes. The present study shows that the canines in both the maxilla and mandible (i.e., $\mathrm{C}^{\prime}, \mathrm{C}$,) were the teeth with the greatest sexual dimorphism, with larger values that were statistically significant in males compared to females. The canines also appeared in 33 out of the 40 logit equations developed, and provided percentages of correct sex assignment of $80.4-94.9 \%$ in combination with measurements from the other teeth. The canines were followed by the mandibular second molar $\left(\mathrm{M}_{2}\right)$, the maxillary and mandibular second premolars $\left(\mathrm{PM}^{2}, \mathrm{PM}_{2}\right)$, the maxillary and mandibular first premolars $\left(\mathrm{PM}^{1}, \mathrm{PM}_{1}\right)$, and the mandibular first molar $\left(\mathrm{M}_{1}\right)$. These data are consistent with the findings of previous studies on the greater sexual dimorphism of the canines (Acharya \& Mainali, 2007; Adams \& Pilloud, 2019; Angadi et al., 2013; Capitaneanu et al., 2017; De Angelis et al., 2015; Flohr, Kierdorf, \& Kierdorf, 2016; Gonçalves, Granja, Cardoso, \& de Carvalho, 2014; Hassett, 2011; Işcan \& Kedici, 2003; Kazzazi \& Kranioti, 2018; Khamis et al., 2014; 
TABLE 7 Summary of the comparisons of sex assignment by odontometrics and biological sex for the experimental subsample

\begin{tabular}{|c|c|c|c|c|}
\hline Individual & Age (years) & Biological sex & Odontometric sex ${ }^{a}$ & Sex assignment match \\
\hline $011 \mathrm{M}$ & 17 & Male & Male & Match \\
\hline $023 \mathrm{~F}$ & 8 & Female & Female & Match \\
\hline 024F & 9 & Female & b & \\
\hline 025F & 18 & Female & Female & Match \\
\hline 029M & 19 & Male & Female & Mismatch \\
\hline 039F & 17 & Female & Female & Match \\
\hline 039M & 11 & Male & $\mathrm{b}$ & \\
\hline $043 \mathrm{M}$ & 18 & Male & Male & Match \\
\hline $046 \mathrm{~F}$ & 16 & Female & Female & Match \\
\hline 050M & 16 & Male & Male & Match \\
\hline 051M & 20 & Male & Male & Match \\
\hline $065 \mathrm{M}$ & 15 & Male & Male & Match \\
\hline $068 \mathrm{~F}$ & 18 & Female & Female & Match \\
\hline 069M & 14 & Male & Male & Match \\
\hline 070M & 20 & Male & Male & Match \\
\hline $081 \mathrm{M}$ & 11 & Male & b & \\
\hline $091 \mathrm{~F}$ & 20 & Female & Female & Match \\
\hline 098F & 18 & Female & Female & Match \\
\hline 099F & 18 & Female & Female & Match \\
\hline 099M & 19 & Male & Male & Match \\
\hline $110 \mathrm{M}$ & 20 & Male & Female & Mismatch \\
\hline $114 \mathrm{M}$ & 18 & Male & Male & Match \\
\hline $133 \mathrm{M}$ & 19 & Male & Male & Match \\
\hline $140 \mathrm{M}$ & 20 & Male & Male & Match \\
\hline $142 \mathrm{M}$ & 15 & Male & b & \\
\hline $165 \mathrm{M}$ & 19 & Male & Male & Match \\
\hline
\end{tabular}

${ }^{\text {aT }}$ The final odontometric sex assignment was based on the criteria described in Section 3.5.

${ }^{b}$ None of the logit equations developed in this study could be applied.
Luna, 2019; Martins Filho, Lopez-Capp, Biazevic, \& Michel-Crosato,2016; Pereira, Bernardo, Pestana, Santos, \& de Mendonça, 2010; Shaweesh, 2017; Tardivo et al., 2015; Thompson, 2013; Viciano et al., 2011, 2015, 2013; Zorba et al., 2011), and on the sexual dimorphism of both maxillary and mandibular first and second premolars (Adams \& Pilloud, 2019; Kazzazi \& Kranioti, 2018; Shaweesh, 2017; Yong et al., 2018; Zorba et al., 2011) and mandibular first and second molars (Acharya \& Mainali, 2007; Adams \& Pilloud, 2019; Angadi et al., 2013; Aris et al., 2018; Kazzazi \& Kranioti, 2018; Martins Filho et al., 2016; Peckmann et al., 2015; Tuttösí \& Cardoso, 2015; Viciano et al., 2015, 2013; Zorba et al., 2012, 2011). Moreover, several crown and cervical measurements of the maxillary and mandibular incisors (i.e., $I^{1}, I_{1}, I^{2}, I_{2}$ ) and third molars (i.e., $\mathrm{M}^{3}, \mathrm{M}_{3}$ ) also showed significant differences between males and females in the present study, and this finding is consistent with other studies (Acharya \& Mainali, 2007; Adams \& Pilloud, 2019; Ateş, Karaman, Işcan, \& Erdem, 2006; Condon et al., 2011; Kazzazi \& Kranioti, 2018; Peckmann et al., 2016, 2015; Staka, Asllani-Hoxha, \& Bimbashi, 2016; Viciano et al., 2015, 2013). Measurements of the incisors and the third molars were particularly effective for sex estimation in combination with measurements from other teeth, such as the canines and the second molars, providing correct sex assignment of $80.5-94.9 \%$.

The main concern in the present study was the possibility that mortality bias would affect the odontometrics of the permanent dentition. If this were the case, the sexual dimorphism of dental metrics presented by adult and nonadult individuals would be different, and therefore, would not be comparable across these individuals. The individuals studied here do not represent a single population, but are instead representative of mortality. Thus, the mortality bias of the studied sample might have some impact on differences in sizes and the sexual dimorphism for dental metrics between the adult and nonadult individuals.

Dental metrics has been the subject of numerous investigations to determine the patterns of variability between different teeth and the relative influence of genetic and environmental factors. Most evidence has suggested that the variation observed for tooth size of the permanent dentition is strongly genetically controlled (Alvesalo \& Tigerstedt, 1974; Garn, Lewis, \& Walenga, 1968; Kieser, 1990). However, differences in the quality of the environment during the complex process of odontogenesis (e.g., malnutrition, disease, climate, 


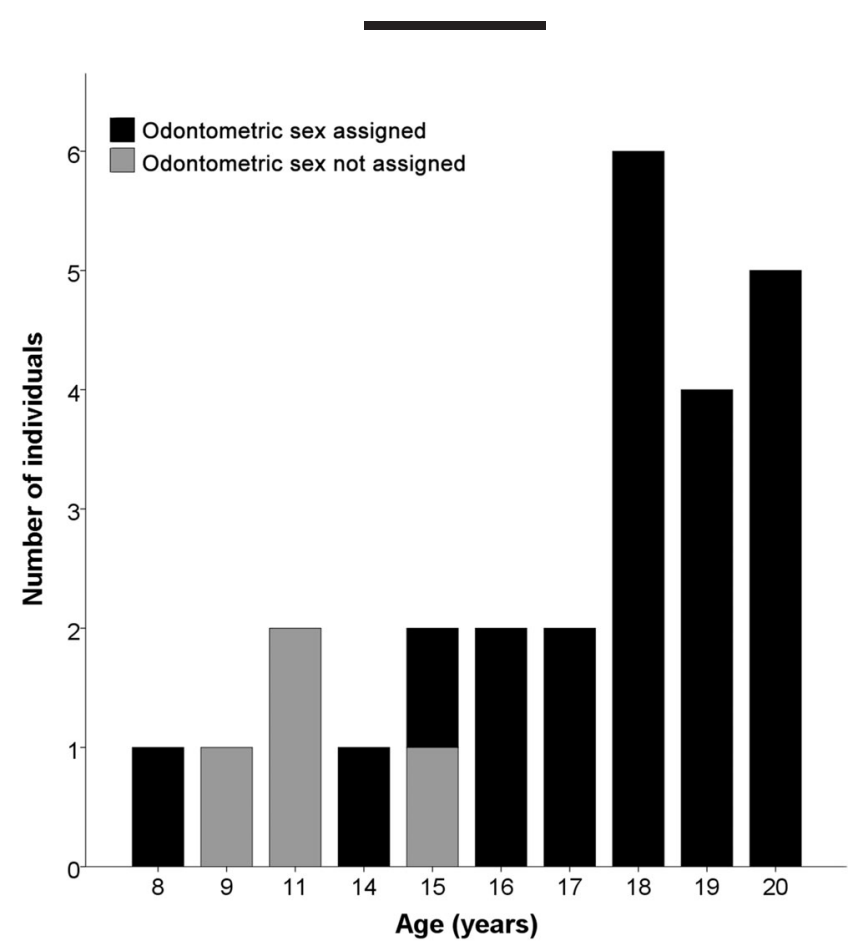

FIGURE 2 Distribution of the odontometric sex assignment of the immature individuals by age of death

subsistence patterns, other negative factors) might influence tooth size and morphology, and ultimately early death occurs among the most susceptible members of the population (Riga, Belcastro, \& Moggi-Cecchi, 2014; Stojanowski, Larsen, Tung, \& McEwan, 2007). Several studies have related skeletal manifestations of biological stress to the reduction in size of the permanent teeth as a result of the early deaths of nonadult individuals (Conceiçao \& Cardoso, 2011; Stojanowski et al., 2007; Ządzińska, Lorkiewicz, Kurek, \& BorowskaStrugińska, 2015). Although a link has been suggested between reduced tooth size and physiological stressors in nonadult individuals (Guagliardo, 1982; Simpson, Hutchinson, \& Larsen, 1990; Stojanowski, 2005; Stojanowski et al., 2007), any correspondence between nonadults mortality bias and the pathological indicators of poor health has been inconsistent and sporadic between different populations (Cardoso, 2008; Stojanowski et al., 2007). For example, in an archeological context, Stojanowski (2005) documented that although the nonadult individuals from the community of San Pedro y San Pablo de Patale (in Apalachee Province, in the Florida panhandle, USA) had smaller teeth than the adults, this community appeared to be in relatively good health, which provided little evidence for increased stress or morbidity. In the present study, the analysis that was performed to evaluate differences in teeth sizes between adults and nonadult individuals did not show significant differences, which suggests that any potential impact of biological stress in early life was negligible. Thus, odontometric characteristics of the nonadult individuals appeared not to be influenced by either nutritional or physiological stressors.

Nevertheless, this statement must be interpreted with some caution, as the nonadults sample here were mainly composed of individuals who died in the last stages of adolescence (i.e., $57.69 \%$ aged 18-20 years), and only four individuals died during childhood (i.e., $15.38 \%$ aged $8-11$ years), who might have lived under relatively poor health conditions that affected their teeth sizes. In the present study, after the application of the binary logistic regression equations based on dental measurements of adult individuals to the teeth of the 26 nonadult individuals of the same population, sex could be estimated in a total of 22. Comparison of the sex estimated by odontometrics with the known biological sex showed matches in $90.9 \%$ of cases. Despite the aforementioned limitations of the age/mortality bias of the nonadults sample, the high consistency of the estimated odontometric sex with the biological sex in nonadult individuals indicates that these measurements of the permanent dentition can indeed be used successfully for sex estimation of non-adult skeletal remains in this sample.

According to Nelson and Ash Jr. (2010), calcification of the permanent teeth is entirely postnatal (i.e., from birth to 10 years, including the third molar). The first molars are the first of the permanent teeth to complete crown formation (at 2.5-3.0 years old) and to emerge into the oral cavity (at 6-7 years old). These are followed by the first and second incisors (maxillary incisors: crown formation at 4-5 years old, emergence at 7-9 years old; mandibular incisors: emergence at 6-8 years old). Then the first premolars (crown formation at 5-6 years old, emergence at 10-11 years old), and canine and second premolars (canines: crown formation at 6-7 years old, emergence at 9-12 years old; second premolars: emergence at 10-12 years old). Finally, the second molars (crown formation at 7-8 years old, emergence at 11-13 years old). As a result, the logit equations developed in this study demonstrate that the odontometric characteristics of the permanent teeth can be used for sex estimation in the early stages of development of nonadult individuals. This can be seen for the early age of 5-6 years, whereby logit equation $L_{10}$ can be applied after crown formation of the first premolar. As the individual's age progresses and dental crowns are completely formed in the tooth crypts or the oral cavity, more of the logit equations can be applied.

In addition, this study has allowed us to demonstrate the importance of the cervical dimensions of the teeth, as 18 of the logit equations developed here use only the cervical measurements, compared with 22 of these logit equations that use a cervical measurement in combination with a crown measurement. This finding is consistent with several other studies that have reported greater success for sex estimation using cervical rather than crown measurements (e.g., Adams \& Pilloud, 2019; Hassett, 2011; Kazzazi \& Kranioti, 2018; Viciano et al., 2013). Studies such as those of Aubry (2014), Hillson et al. (2005), Pilloud and Hillson (2012) and Viciano, Alemán, D'Anastasio, and Capasso (2012) have shown moderate to significant correlations between crown measurements with their equivalents at the cervical level of the tooth, which would indicate according to Adams and Pilloud (2019) that although similar information is conveyed in these measurements, these might represent differences due to genotype. Thus, as the dental cervical region is a good predictor of sex, its measurement allows greater applicability of the odontometric technique in cases where several limiting factors of multiple origin might 
affect the available crowns of the teeth (e.g., greater dental wear, hypoplastic defects, cariogenic cavities, dental restorations), with lesser degree of involvement at the cervical level.

Although the subjectivity of descriptive morphological methods for sex estimation of nonadult individuals has led to the implementation of ordinal scoring systems and statistical analyses (Krishan et al., 2016), metric methods are favored because of the objectivity associated with metric data. However, despite there being so many diverse odon-tometric applications in clinical dentistry (e.g., prosthodontic tooth selection, implant selection) and physical anthropology (e.g., sex estima-tion, ancestry estimation), it is known that there are margins of error inherent in these methods (Perini, de Oliveira, Omelia, \& de Oliveira, 2005). Thus, when dental measurements are repeated, differ-ences in the diverse measurements can occur as a result of the different sources of variation, such as: (a) biological variation of the teeth that is attributable to the diversity of the physical characteristics of a popula-tion analyzed; (b) variation due to the measuring instrument(s); and (c) variations attributable to the examiners. The first of these sources of variation cannot be avoided, while the last two sources can essentially be avoided, or at least minimized, to a large degee.

Determination of the levels of agreement between repeated measurements collected by the same and different examiners is an impor-tant concem in any metric study, such as the present one. Here, the ICCs showed high reproducibility in the intraexaminer error analysis (i.e., "excellent" agreements), which indicated that the repeated dental measurements collected by the principal examiner (who is highly experienced in odontometrics) were particularly reliable. For the inter-examiner error analysis, the secondary examiner had no prior experi-ence in odontometrics but was trained by the principal examiner here prior to the beginning of the present study. The overall data for inter-examiner error showed lower ICCs (which ranged from "good" to "excellent" agreement) in comparison with the intraexaminer error. The ICCs between the examiners tended to be a little lower for the molars, and to some extent for the premolars, than for the incisors and canines. For the molars, the crown diameters were more difficult to measure consistently than the cervical diameters, as it can be more difficult to measure the diagonal diameters than the mesiodistal and buccolingual diameters. The data here are consistent with those of Aubry (2014), Hillson et al. (2005) and Viciano et al. (2013), who found that the variation in the morphology of molars makes it difficult to find standard crown measurement locations. Thus, analysts are forced to consider other means of measuring teeth. For the premolars, the cervical diameters are more difficult to measure consistently than the crown diameters because the crowns do not flare out above the cement enamel-junction (which can be used as reference point for cervical measurements); this difference is less marked cervically, mak-ing it difficult to take measurements consistently. According to Harris and Smith (2009), the reproducibility of dental measurements is highly dependent on human judgment, because these measurements rely on greater or lesser accessibility of the defining landmarks, and/or if they are well delimited.

Although the level of agreement between the repeated measurements in the present study showed that dental measurements are reproducible and concordant within and between examiners, the slight differences between the different examiners can be attributed to the difficulties for the measurements of certain tooth dimensions. Thus, to improve the accuracy of the methodological procedures and the correct use of the binary logistic regression equations developed for odontometric sex estimation, it is mandatory that the examiners have knowledge in dental morphology as well as minimal training in the correct localization of the landmarks for the collection of the dif-ferent dental measurements.

In summary, all these considerations emphasize the importance of the present study for sex estimation of nonadult human skeletal remains. This study reinforces and extends previous studies that have proposed that when completely formed dental crowns are present in the tooth crypts or the teeth have emerged into the oral cavity, odon-tometric analysis of the permanent dentition is an objective and rapid technique for sex estimation of nonadult skeletal remains in forensic cases and in archeological settings. Therefore, odontometrics benefit from the advantages of lack of expression of sex-related skeletal char-acteristics in sexually immature individuals, better preservation of teeth than bone tissue, and metric approaches. Moreover, this tech-nique is easier to apply in situations where preservation of skeletal remains is not optimal and/ or only the dentition is recovered.

\section{AUTHOR CONTRIBUTIONS}

Joan Viciano: Conceptualization; data curation; formal analysis; investigation; methodology; supervision; validation; visualization; writing-original draft; writing-review and editing. Carmen Tanga: Conceptualization; data curation; formal analysis; investigation; methodology; validation; visualization; writing-original draft; writing-review and editing. Ruggero D'Anastasio: Writing-original draft; writing-review and editing Maria Giovanna Belcastro: Writing-original draft; writing-review and editing. Luigi Capasso: Writing-original draft; writing-review and editing.

\section{DATA AVAILABILITY STATEMENT}

The data that support the findings of this study are available from the corresponding author upon reasonable request. The data are not pub-licly available due to privacy or ethical restrictions.

\section{ORCID}

Joan Viciano https://orcid.org/0000-0001-7575-557X

Ruggero D'Anastasio https://orcid.org/0000-0001-5508-2419

Maria Giovanna Belcastro https://orcid.org/0000-0002-8932-8509

\section{REFERENCES}

Acharya, A. B., \& Mainali, S. (2007). Univariate sex dimorphism in the Nepalese dentition and the use of discriminant functions in gender assess-ment. Forensic Science International, 173(1), 4756. https://doi.org/10. 1016/j.forsciint.2007.01.024

Adams, D. M., \& Pilloud, M. A. (2019). Sex estimation from dental crown and cervical metrics in a contemporary Japanese sample. Forensic Anthropology, 2(4), 1 11. https://doi.org/10.5744/fa.2019.1008 Albanese, J. (2003). A metric method for sex detennination using the hipbone and the femur. Journal of Forensic Sciences, 48(2), 263273. 
Alvesalo, L., \& Tigerstedt, P. M. (1974). Heritabilities of human tooth dimensions. Hereditas, 77(2), 311 318. https://doi.org/10.1111/j. 1601-5223.1974.tb00943.x

Angadi, P. V., Hemani, S., Prabhu, S., \& Acharya, A. B. (2013). Analyses of odontometric sexual dimorphism and sex assessment accuracy on a large sample. Journal of Forensic and Legal Medicine, 20(6), 673677. https://doi.org/10.1016/j.jflm.2013.03.040

Aris, C., Nystrom, P., \& Craig-Atkins, E. (2018). A new multivariate method for determining sex of immature human remains using the maxillary first molar. American Journal of Physical Anthropology, 167(3), 672683. https://doi.org/10.1002/ajpa.23695

Ateş, M., Karaman, F., Işcan, M. Y., \& Erdem, T. L. (2006). Sexual differences in Turkish dentition. Legal Medicine, 8(5), 288 292. https://doi. org/10.1016/j.legalmed.2006.06.003

Aubry, B. S. (2014). Technical note: Cervical dimensions for in situ and loose teeth: A critique of the Hillson et al. (2005) method. American Journal of Physical Anthropology, 154(1), 159 164. https://doi.org/10. 1002/ajpa.22475

Bartlett, J. W., \& Frost, C. (2008). Reliability, repeatability and reproducibility: Analysis of measurement errors in continuous variables. Ultrasound in Obstetrics and Gynecology, 31(4), 466 475. https://doi.org/ 10.1002/uog.5256

Belcastro, M. G., Bonfiglioli, B., Pedrosi, M. E., Zuppello, M., Tanganelli, V., \& Mariotti, V. (2017). The history and composition of the identified human skeletal collection of the Certosa Cemetery (Bologna, Italy, 19th-20th century). International Journal of Osteoarchaeology, 27(5), 912 925. https://doi.org/10.1002/oa.2605

Beyer-Olsen, E. M. S., \& Alexandersen, V. (1995). Sex assessment of medieval Norwegian skeletons based on permanent tooth crown size. International Journal of Osteoarchaeology, 5(3), 274 281. https://doi.org/ 10.1002/oa.1390050306

Capitaneanu, C., Willems, G., Jacobs, R., Fieuws, S., \& Thevissen, P. (2017). Sex estimation based on tooth measurements using panoramic radiographs. International Journal of Legal Medicine, 131(3), 813821. https://doi.org/10.1007/s00414-016-1434-0

Cardoso, H. F. V. (2008). Sample-specific (universal) metric approaches for determining the sex of immature human skeletal remains using permanent tooth dimensions. Journal of Archaeological Science, 35(1), 158 168. https://doi.org/10.1016/j.jas.2007.02.013

Cardoso, H. F. V., \& Saunders, S. R. (2008). Two arch criteria of the ilium for sex determination of immature skeletal remains: A test of their accuracy and an assessment of intra- and inter-observer error. Forensic Science International, 178(1), 24 29. https://doi.org/10.1016/j. forsciint.2008.01.012

Conceição, E. L. N., \& Cardoso, H. F. V. (2011). Environmental effects on skeletal versus dental development II: Further testing of a basic assumption in human osteological research. American Journal of Physical Anthropology, 144(3), 463 470. https://doi.org/10.1002/ajpa.21433

Condon, M., Bready, M., Quinn, F., O'Connell, B. C., Houston, F. J., \& O'Sullivan, M. (2011). Maxillary anterior tooth dimensions and proportions in an Irish young adult population. Journal of Oral Rehabilitation, 38(7), 501 508. https://doi.org/10.1111/j.1365-2842. 2010.02181.x

De Angelis, D., Gibelli, D., Gaudio, D., Noce, F. C., Guercini, N., Varvara, G., ... Cattaneo, C. (2015). Sexual dimorphism of canine volume: A pilot study. Legal Medicine, 17(3), 163 166. https://doi.org/10.1016/j. legalmed.2014.12.006

De Menezes Oliveira, M. A., Torres, C. P., Gomes-Silva, J. M. Chinelatti, M. A., De Menezes, F. C., Palma-Dibb, R. G., \& Borsatto, M. C. (2010). Microstructure and mineral composition of dental enamel of permanent and deciduous teeth. Microscopy Research and Technique, 73(5), 572 577. https://doi.org/10.1002/jemt.20796

De Vito, C., \& Saunders, S. (1990). A discriminant function analysis of deciduous teeth to determine sex. Journal of Forensic Sciences, 35(4), 845 858. https://doi.org/10.1520/JFS12897J
Duckworth, R. M. (2006). The teeth and their environment: Physical, chemical and biochemical influences. Basel: Karger.

Flohr, S., Kierdorf, U., \& Kierdorf, H. (2016). Odontometric sex estimation in humans using measurements on permanent canines. A comparison of an early Neolithic and an early medieval assemblage from Germany. Anthropologischer Anzeiger, 73(3), 225 233. https://doi.org/10.1127/ anthranz/2016/0626

Franklin, D., Oxnard, C. E., O'Higgins, P., \& Dadour, I. (2007). Sexual dimorphism in the subadult mandible: Quantification using geometric morphometrics. Journal of Forensic Sciences, 52(1), 6 10. https://doi.org/ 10.1111/j.1556-4029.2006.00311.x

Garcia-Godoy, F., Michelen, A., \& Townsend, G. (1985). Crown diameters of the deciduous teeth in Dominican Mulatto children. Human Biology, 57(1), 27 31. https://doi.org/10.2307/41463630

Garn, S. M., Lewis, A. B., Swindler, D. R., \& Kerewsky, R. S. (1967). Genetic control of sexual dimorphism in tooth size. Journal of Dental Research, 46(5), 963 972. https://doi.org/10.1177/00220345670460055801

Garn, S. M., Lewis, A. B., \& Walenga, A. J. (1968). Genetic basis of the crown-size profile pattern. Journal of Dental Research, 47(6), 1190 1190. https://doi.org/10.1177/00220345680470063601

Gonçalves, D., Granja, R., Cardoso, F. A., \& de Carvalho, A. F. (2014). Sample-specific sex estimation in archaeological contexts with commingled human remains: A case study from the Middle Neolithic cave of Bom Santo in Portugal. Journal of Archaeological Science, 49(1), 185191. https://doi.org/10.1016/j.jas.2014.05.011

Gouveia, M. F., Oliveira Santos, I., Santos, A. L., \& Gonçalves, D. (2017). Sample-specific odontometric sex estimation: A method with potential application to burned remains. Science and Justice, 57(4), 262269. https://doi.org/10.1016/j.scijus.2017.03.001

Guagliardo, M. F. (1982). Tooth crown size differences between age groups: A possible new indicator of stress in skeletal samples. American Journal of Physical Anthropology, 58(4), 383 389. https://doi.org/ 10.1002/ajpa.1330580405

Harris, E. F., \& Smith, R. N. (2009). Accounting for measurement error: A critical but often overlooked process. Archives of Oral Biology, 54 (Suppl. 1), S107 S117. https://doi.org/10.1016/j.archoralbio.2008. 04.010

Hassett, B. (2011). Technical note: Estimating sex using cervical canine odontometrics: A test using a known sex sample. American Journal of Physical Anthropology, 146(3), 486 489. https://doi.org/10.1002/ajpa. 21584

Hillson, S. (1996). Dental anthropology. Cambridge: Cambridge University Press.

Hillson, S., FitzGerald, C., \& Flinn, H. (2005). Alternative dental measurements: Proposals and relationships with other measurements. American Journal of Physical Anthropology, 126(4), 413 426. https://doi.org/ 10.1002/ajpa.10430

Hunt, E. E., Jr., \& Gleiser, I. (1955). The estimation of age and sex of preadolescent children from bones and teeth. American Journal of Physical Anthropology, 13(3), $479487 . \quad$ https://doi.org/10.1002/ajpa. 1330130308

IBM Corp. (2013). IBM SPSS Statistics for Windows. Armonk, NY: IBM Corp.

Irurita, J., \& Alemán, I. (2016). Validation of the sex estimation method elaborated by Schutkowski in the Granada Osteological Collection of identified infant and young children: Analysis of the controversy between the different ways of analyzing and interpreting the results. International Journal of Legal Medicine, 130(6), 1623 1632. https://doi. org/10.1007/s00414-016-1354-z

İşcan, M. Y., \& Kedici, P. S. (2003). Sexual variation in bucco-lingual dimensions in Turkish dentition. Forensic Science International, 137(2 3), 160 164. https://doi.org/10.1016/S0379-0738(03) 00349-9

Kazzazi, S. M., \& Kranioti, E. F. (2017). A novel method for sex estimation using 3D computed tomography models of tooth roots: A volumetric 
analysis. Archives of Oral Biology, 83, 202 208. https://doi.org/10. 1016/j.archoralbio.2017.07.024

Kazzazi, S. M., \& Kranioti, E. F. (2018). Sex estimation using cervical dental measurements in an archaeological population from Iran. Archaeological and Anthropological Sciences, 10(2), 439 448. https://doi.org/10. 1007/s12520-016-0363-7

Khamis, M. F., Taylor, J. A., Malik, S. N., \& Townsend, G. C. (2014). Odontometric sex variation in Malaysians with application to sex prediction. Forensic Science International, 234, 183.e1 183.e7. https://doi.org/10. 1016/j.forsciint.2013.09.019

Kieser, J. A. (1990). Human adult odontometrics: The study of variation in adult tooth size. Cambridge: Cambridge University Press.

Koo, T. K., \& Li, M. Y. (2016). A guideline of selecting and reporting intraclass correlation coefficients for reliability research. Journal of Chiropractic Medicine, 15(2), 155 163. https://doi.org/10.1016/j.jcm. 2016.02.012

Krishan, K., Chatterjee, P. M., Kanchan, T., Kaur, S., Baryah, N., \& Singh, R. K. (2016). A review of sex estimation techniques during examination of skeletal remains in forensic anthropology casework. Forensic Science International, 261, 165 165. https://doi.org/10.1016/ j.forsciint.2016.02.007

Lewis, M. E. (2006). The bioarchaeology of children: Perspectives from biological and forensic Anthropology. Cambridge: Cambridge University Press. https://doi.org/10.1017/СBO9780511542473

López-Lázaro, S., Alemán, I., Viciano, J., Irurita, J., \& Botella, M. C. (2018). Sexual dimorphism of the first deciduous molar: A geometric morphometric approach. Forensic Science International, 290, 94 102. https:// doi.org/10.1016/j.forsciint.2018.06.036

Loth, S. R., \& Henneberg, M. (2001). Sexually dimorphic mandibular morphology in the first few years of life. American Journal of Physical Anthropology, 115(2), 179 186. https://doi.org/10.1002/ajpa. 1067

Luna, L. H., Aranda, C. M., \& Santos, A. L. (2017). New method for sex prediction using the human non-adult auricular surface of the ilium in the collection of identified skeletons of the University of Coimbra. International Journal of Osteoarchaeology, 27(5), 898 911. https://doi.org/10. 1002/oa.2604

Luna, L. H. (2019). Canine sex estimation and sexual dimorphism in the collection of identified skeletons of the University of Coimbra, with an application in a Roman cemetery from Faro, Portugal. International Journal of Osteoarchaeology, 29(2), 260 272. https://doi.org/10.1002/ oa. 2734

Martins Filho, I. E., Lopez-Capp, T. T., Biazevic, M. G. H., \& MichelCrosato, E. (2016). Sexual dimorphism using odontometric indexes: Analysis of three statistical techniques. Journal of Forensic and Legal Medicine, 44, 37 42. https://doi.org/10.1016/j.jflm.2016. 08.010

Molleson, T., Cruse, K., \& Mays, S. (1998). Some sexually dimorphic features of the human juvenile skull and their value in sex determination in immature skeletal remains. Journal of Archaeological Science, 25(8), 719 728. https://doi.org/10.1006/jasc.1997.0215

Nelson, S. J., \& Ash, M. M., Jr. (2010). Wheeler's dental anatomy, physiology and occlusion (9th ed.). St. Louis: Saunders.

Okazaki, K. (2005). Sex assessment of subadult skeletons based on tooth crown measurements: An examination on the interpopulational variation of sex differences and an application to excavated skeletons. Anthropological Science (Japanese Series), $113(2), 139$ 159. https://doi. org/10.1537/asj.113.139

Paknahad, M., Vossoughi, M., \& Ahmadi Zeydabadi, F. (2016). A radioodontometric analysis of sexual dimorphism in deciduous dentition. Journal of Forensic and Legal Medicine, 44, 54 57. https://doi.org/10. 1016/j.jflm.2016.08.017

Peckmann, T. R., Logar, C., Garrido-Varas, C. E., Meek, S., \& Pinto, X. T. (2016). Sex determination using the mesio-distal dimension of permanent maxillary incisors and canines in a modern Chilean population.
Science \& Justice, 56(2), 84 89. https://doi.org/10.1016/j.scijus.2015. 10.002

Peckmann, T. R., Meek, S., Dilkie, N., \& Mussett, M. (2015). Sex estimation using diagonal diameter measurements of molar teeth in African American populations. Journal of Forensic and Legal Medicine, 36, 70 80. https://doi.org/10.1016/j.jflm.2015.09.001

Pereira, C., Bernardo, M., Pestana, D., Santos, J. C., \& de Mendonça, M. C. (2010). Contribution of teeth in human forensic identification Discriminant function sexing odontometrical techniques in Portuguese population. Journal of Forensic and Legal Medicine, 17(2), 105110. https://doi.org/10.1016/j.jflm.2009.09.001

Perinetti, G. (2018). StaTips Part IV: Selection, interpretation and reporting of the intraclass correlation coefficient. South European Journal of Orthodontics and Dentofacial Research, 5(1), 3 5. https://doi.org/10. 5937/sejodr5-17434

Perini, T. A., de Oliveira, G. L., Ornelia, J. S., \& de Oliveira, F. P. (2005). Technical error of measurement in anthropometry. Revista Brasileira de Medicina do Esporte, 11(1), 86 90. https://doi.org/10.1590/S151786922005000100009

Pilloud, M. A., \& Hillson, S. (2012). Brief communication: The use of alternative dental measurements on deciduous teeth. American Journal of Physical Anthropology, 149(2), 299 306. https://doi.org/10.1002/ajpa. 22116

Pohar, M., Blas, M., \& Turk, S. (2004). Comparison of logistic regression and linear discriminant analysis: A simulation study. Metodološki Zvezki, 1(1), 143161.

Riga, A., Belcastro, M. G., \& Moggi-Cecchi, J. (2014). Environmental stress increases variability in the expression of dental cusps. American Journal of Physical Anthropology, 153(3), 397 407. https://doi.org/10.1002/ ajpa. 22438

Rösing, F. W. (1983). Sexing immature human skeletons. Journal of Human Evolution, 12(2), 149 155. https://doi.org/10.1016/S0047-2484(83) 80020-7

Schmidt, C. W., \& Symes, S. (2015). The analysis of burned human remains (2nd ed.). London: Academic Press.

Schutkowski, H. (1993). Sex determination of infant and juvenile skeletons: I. Morphognostic features. American Journal of Physical Anthropology, 90(2), 199 205. https://doi.org/10.1002/ajpa. 1330900206

Shankar, S., Anuthama, K., Kruthika, M., Kumar, V. S., Ramesh, K., Jaheerdeen, A., \& Yasin, M. M. (2013). Identifying sexual dimorphism in a paediatric South Indian population using stepwise discriminant function analysis. Journal of Forensic and Legal Medicine, 20(6), 752 756. https://doi.org/10.1016/j.jflm.2013.04.009

Shaweesh, A. I. (2017). Mesiodistal and faciolingual diameters of the permanent teeth in a Jordanian population. Archives of Oral Biology, 73, 253 258. https://doi.org/10.1016/j.archoralbio.2016. 10.026

Simpson, S. W., Hutchinson, D. L., \& Larsen, C. S. (1990). Coping with stress: Tooth size, dental defects, and age-at-death. In C. S. Larsen (Ed.), The archaeology of mission Santa Catalina de Guale, Part 2: Biocultural interpretations of a population in transition. Anthropological Papers of the American Museum of Natural History, No. 68 (pp. 66 77). New York: American Museum of Natural History.

Singh, A., Bhatia, H. P., Sood, S., \& Sharma, N. (2017). Demystifying the mysteries: Sexual dimorphism in primary teeth. Journal of Clinical and Diagnostic Research, 11(4), 110 114. https://doi.org/10.7860/JCDR/ 2017/25237.9744

Smith, B. H. (1984). Patterns of molar wear in hunter-gatherers and agriculturalists. American Journal of Physical Anthropology, 63(1), 3956. https://doi.org/10.1002/ajpa.1330630107

Sonika, V., Harshaminder, K., Madhushankari, G. S., \& Sri Kennath, J. A. A. (2011). Sexual dimorphism in the permanent maxillary first molar: A study of the Haryana population (India). Journal of Forensic OdontoStomatology, 29(1), 3743. 
Staka, G., Asllani-Hoxha, F., \& Bimbashi, V. (2016). Sexual dimorphism in permanent maxillary central incisor in Kosovo-Albanian population. International Journal of Morphology, 34(3), 1176 1180. https://doi.org/ $10.4067 / \mathrm{s} 0717-95022016000300059$

Stojanowski, C. M. (2005). Biological structure of the San Pedro y San Pablo de Patale mission cemetery. Southeastern Archaeology, 24(2), 165179

Stojanowski, C. M., Larsen, C. S., Tung, T. A., \& McEwan, B. G. (2007). Biological structure and health implications from tooth size at Mission San Luis de Apalachee. American Journal of Physical Anthropology, 132 (2), 207 222. https://doi.org/10.1002/ajpa.20489

Stull, K. E., \& Godde, K. (2013). Sex estimation of infants between birth and one year through discriminant analysis of the humerus and femur. Journal of Forensic Sciences, 58(1), 13 20. https://doi.org/10.1111/j. 1556-4029.2012.02286.x

Stull, K. E., L'Abbé, E. N., \& Ousley, S. D. (2017). Subadult sex estimation from diaphyseal dimensions. American Journal of Physical Anthropology, 163(1), 64 74. https://doi.org/10.1002/ajpa.23185

Sutter, R. C. (2003). Nonmetric subadult skeletal sexing traits: I. A blind test of the accuracy of eight previously proposed methods using prehistoric known-sex mummies from northern Chile. Journal of Forensic Sciences, 48(5), 927 935. https://doi.org/10.1520/JFS2002302

Tardivo, D., Sastre, J., Catherine, J.-H., Leonetti, G., Adalian, P., \& Foti, B. (2015). Gender determination of adult individuals by threedimensional modeling of canines. Journal of Forensic Sciences, 60(5), 1341 1345. https://doi.org/10.1111/1556-4029.12821

Thompson, A. R. (2013). Odontometric determination of sex at Mound 72. Cahokia. American Journal of Physical Anthropology, 151(3), 408 419. https://doi.org/10.1002/ajpa.22282

Tuttösí, P., \& Cardoso, H. F. V. (2015). An assessment of sexual dimorphism and sex estimation using cervical dental measurements in a Northwest Coast archeological sample. Journal of Archaeological Science: Reports, 3, 306 312. https://doi.org/10.1016/j.jasrep.2015. 06.018

Ulijaszek, S. J., \& Kerr, D. A. (1999). Anthropometric measurement error and the assessment of nutritional status. British Journal of Nutrition, 82 (3), 165 177. https://doi.org/10.1017/s0007114599001348

Vallois, H. V. (1960). Vital statistics in prehistoric populations as determined from archaeological data. In R. F. Heizer \& S. F. Cook (Eds.), The application of quantitative methods in archaeology (pp. 186 222). Chicago: Quadrangle Books.

Viciano, J., Alemán, I., D'Anastasio, R., \& Capasso, L. (2012). Alternative dental measurements: Correlation between cervical and crown dimensions. Journal of Biological Research (Italy), 85(1), 194 200. https://doi. org/10.4081/jbr.2012.4105

Viciano, J., Alemán, I., D'Anastasio, R., Capasso, L., \& Botella, M. C. (2011). Odontometric sex discrimination in the Herculaneum sample (79 AD, Naples, Italy), with application to juveniles. American Journal of Physical Anthropology, 145(1), 97 106. https://doi.org/10.1002/ajpa.21471

Viciano, J., D'Anastasio, R., \& Capasso, L. (2015). Odontometric sex estimation on three populations of the Iron Age from Abruzzo region (central-southern Italy). Archives of Oral Biology, 60(1), 100 115. https:// doi.org/10.1016/j.archoralbio.2014.09.003

Viciano, J., López-Lázaro, S., \& Alemán, I. (2013). Sex estimation based on deciduous and permanent dentition in a contemporary Spanish population. American Journal of Physical Anthropology, 152(1), 3143. https://doi.org/10.1002/ajpa.22324

Vlak, D., Roksandic, M., \& Schillaci, M. A. (2008). Greater sciatic notch as a sex indicator in juveniles. American Journal of Physical Anthropology, 137(3), 309 315. https://doi.org/10.1002/ajpa.20875

Vodanović, M., Demo, Ž., Njemirovskij, V., Keros, J., \& Brkić, H. (2007). Odontometrics: A useful method for sex determination in an archaeological skeletal population? Journal of Archaeological Science, 34(6), 905 913. https://doi.org/10.1016/j.jas.2006.09.004

Weaver, D. S. (1980). Sex differences in the ilia of a known sex and age sample of fetal and infant skeletons. American Journal of Physical Anthropology, 52(2), 191 195. https://doi.org/10.1002/ajpa.1330520205

Wilson, P. R., \& Beynon, A. D. (1989). Mineralization differences between human deciduous and permanent enamel measured by quantitative microradiography. Archives of Oral Biology, 34(2), 85 88. https://doi. org/10.1016/0003-9969(89)90130-1

Yong, R., Ranjitkar, S., Lekkas, D., Halazonetis, D., Evans, A., Brook, A., \& Townsend, G. (2018). Three-dimensional (3D) geometric morphometric analysis of human premolars to assess sexual dimorphism and biological ancestry in Australian populations. American Journal of Physical Anthropology, 166(2), 373 385. https://doi.org/10.1002/ajpa.23438

Żądzińska, E., Karasińska, M., Jedrychowska-Dańska, K., Watala, C., \& Witas, H. W. (2008). Sex diagnosis of subadult specimens from Medieval Polish archaeological sites: Metric analysis of deciduous dentition. Homo, 59(3), 175 187. https://doi.org/10.1016/j.jchb.2008.04.004

Ządzińska, E., Lorkiewicz, W., Kurek, M., \& Borowska-Strugińska, B. (2015). Accentuated lines in the enamel of primary incisors from skeletal remains: A contribution to the explanation of early childhood mortality in a medieval population from Poland. American Journal of Physical Anthropology, 157(3), 402 410. https://doi.org/10.1002/ajpa.22731

Zorba, E., Moraitis, K., Eliopoulos, C., \& Spiliopoulou, C. (2012). Sex determination in modern Greeks using diagonal measurements of molar teeth. Forensic Science International, 217(1 3), 19 26. https://doi.org/ 10.1016/j.forsciint.2011.09.020

Zorba, E., Moraitis, K., \& Manolis, S. K. (2011). Sexual dimorphism in permanent teeth of modern Greeks. Forensic Science International, 210 (1 3), 74 81. https://doi.org/10.1016/j.forsciint.2011.02.001

Zorba, E., Vanna, V., \& Moraitis, K. (2014). Sexual dimorphism of root length on a Greek population sample. Homo, 65(2), 143 154. https:// doi.org/10.1016/j.jchb.2013.09.005

\section{SUPPORTING INFORMATION}

Additional supporting information may be found online in the Supporting Information section at the end of this article.

How to cite this article: Viciano J, Tanga C, D'Anastasio R, Belcastro MG, Capasso L. Sex estimation by odontometrics of nonadult human remains from a contemporary Italian sample. Am J Phys Anthropol. 2020;e24132. https://doi.org/10.1002/ ajpa.24132 